\title{
Enhanced Excitatory Connectivity and Disturbed Sound Processing in the Auditory Brainstem of Fragile X Mice
}

\author{
Elisabet Garcia-Pino, ${ }^{1}$ Nikodemus Gessele, ${ }^{1}$ and Ursula Koch ${ }^{1,2}$ \\ ${ }^{1}$ Institute of Biology, Neurophysiology, Freie Universität Berlin, 14195 Berlin, Germany, and ${ }^{2}$ NeuroCure Cluster of Excellence, Charité Universitätsmedizin, \\ 10117 Berlin, Germany
}

Hypersensitivity to sounds is one of the prevalent symptoms in individuals with Fragile X syndrome (FXS). It manifests behaviorally early during development and is often used as a landmark for treatment efficacy. However, the physiological mechanisms and circuit-level alterations underlying this aberrant behavior remain poorly understood. Using the mouse model of FXS ( $F m r 1 \mathrm{KO}$ ), we demonstrate that functional maturation of auditory brainstem synapses is impaired in FXS. Fmr1 KO mice showed a greatly enhanced excitatory synaptic input strength in neurons of the lateral superior olive (LSO), a prominent auditory brainstem nucleus, which integrates ipsilateral excitation and contralateral inhibition to compute interaural level differences. Conversely, the glycinergic, inhibitory input properties remained unaffected. The enhanced excitation was the result of an increased number of cochlear nucleus fibers converging onto one LSO neuron, without changing individual synapse properties. Concomitantly, immunolabeling of excitatory ending markers revealed an increase in the immunolabeled area, supporting abnormally elevated excitatory input numbers. Intrinsic firing properties were only slightly enhanced. In line with the disturbed development of LSO circuitry, auditory processing was also affected in adult Fmr1 KO mice as shown with single-unit recordings of LSO neurons. These processing deficits manifested as an increase in firing rate, a broadening of the frequency response area, and a shift in the interaural level difference function of LSO neurons. Our results suggest that this aberrant synaptic development of auditory brainstem circuits might be a major underlying cause of the auditory processing deficits in FXS.

Key words: auditory; brainstem; excitatory synapses; Fragile X; lateral superior olive; sound level

\section{Significance Statement}

Fragile X Syndrome (FXS) is the most common inheritable form of intellectual impairment, including autism. A core symptom of FXS is extreme sensitivity to loud sounds. This is one reason why individuals with FXS tend to avoid social interactions, contributing to their isolation. Here, a mouse model of FXS was used to investigate the auditory brainstem where basic sound information is first processed. Loss of the Fragile X mental retardation protein leads to excessive excitatory compared with inhibitory inputs in neurons extracting information about sound levels. Functionally, this elevated excitation results in increased firing rates, and abnormal coding of frequency and binaural sound localization cues. Imbalanced early-stage sound level processing could partially explain the auditory processing deficits in FXS.

\section{Introduction}

Sensory processing deficits are a common hallmark of several neurodevelopmental disorders (Ben-Sasson et al., 2009; Marco et al., 2011). In Fragile X syndrome (FXS), translational silencing of

Received July 21, 2016; revised June 6, 2017; accepted June 15, 2017.

Author contributions: E.G.-P., N.G., and U.K. designed research; E.G.-P., N.G., and U.K. performed research; E.G.-P., N.G., and U.K. analyzed data; E.G.-P., N.G., and U.K. wrote the paper.

This work was supported by the Deutsche Forschungsgemeinschaft SFB665 to U.K., SPP1608 to U.K., and an European Union Cofund Marie-Curie Fellowship to E.G.-P. We thank Karin Heufelder for establishing and maintaining the Fragile X mouse colony; and Karl Kandler for comments on an earlier version of the manuscript.

The authors declare no competing financial interests.

Correspondence should be addressed to Dr. Ursula Koch, Freie Universität Berlin, Institut für Biologie, AG Neurophysiologie, Takustraße 6, 14195 Berlin, Germany. E-mail: ursula.koch@fu-berlin.de.

DOI:10.1523/JNEUROSCI.2310-16.2017

Copyright $\odot 2017$ the authors $\quad 0270-6474 / 17 / 377403-17 \$ 15.00 / 0$ fragile $\mathrm{x}$ mental retardation protein (FMRP) causes, among several other cognitive and psychiatric symptoms, sensory processing deficits, including hypersensitivity to sensory stimulation (Sinclair et al., 2017). These deficits are accompanied by elevated cortical responses and decreased habituation in response to sensory and especially auditory stimuli (Castrén et al., 2003; Knoth and Lippé, 2012; Van der Molen et al., 2012). The mouse model of FXS (Fmr1 KO) recapitulates this human phenotype displaying elevated cortical evoked responses, defects in startle responses, as well as audiogenic seizures (Musumeci et al., 2000; Chen and Toth, 2001; Rotschafer and Razak, 2013; Knoth et al., 2014), indicating misprocessing of auditory information. However, the fundamental processes underlying sensory hypersensitivity remain poorly understood. 
Recent progress has been made in elucidating physiological and circuit alterations underlying hyperexcitability of cortical and hippocampal networks in FXS. Both voltage-gated channels, such as the hyperpolarization-activated cyclic nucleotide-gated channels (HCN) and the calcium-activated $\mathrm{K}^{+}$channel (BK), as well as excitatory synaptic plasticity mechanisms are affected by the loss of FMRP (Bear et al., 2004; Contractor, 2013; Zhang et al., 2014). Together with a reduced GABAergic inhibition, these alterations result in an elevated excitability of neuronal circuits, yet the contributions of the various factors are brain region specific (Selby et al., 2007; Contractor et al., 2015).

In the auditory cortex of Fmrl KO mice, both response characteristics and learning rules are altered in line with the observed auditory hypersensitivity, indicating abnormal development of auditory cortical circuits (Kim et al., 2013; Rotschafer and Razak, 2013). However, high FMRP expression levels in the auditory brainstem (Wang et al., 2014) suggest that these deficits might originate from disturbed auditory brainstem circuits and are propagated to higher processing centers. In FXS patients, the analysis of auditory brainstem responses revealed prolonged interpeak latencies, indicating dysfunction in auditory brainstem conduction times (Arinami et al., 1988; Ferri, 1989; Wisniewski et al., 1991). Moreover, morphological alterations of the superior olivary complex (SOC) nuclei and neurons have been observed in postmortem tissue of subjects with FXS and autism (Kulesza and Mangunay, 2008; Kulesza et al., 2011). Correspondingly, murine models of FXS display altered auditory brainstem responses and changes in synaptic input density in SOC neurons (Rotschafer et al., 2015). Together, SOC synapses comprise an attractive model to address the brainstem circuit-level alterations underlying auditory hypersensitivity in FXS.

The lateral superior olive (LSO) forms part of the SOC nuclei in the mammalian brainstem and provides extensive excitatory projections to higher-order auditory centers. LSO neurons encode interaural level differences (ILDs), which are one of the major cues for localizing sound in the horizontal plane (Tollin, 2003; Grothe et al., 2010). This is achieved by integrating the excitatory inputs from the ipsilateral ventral cochlear nucleus (VCN) with the inhibitory inputs (GABAergic/glycinergic) from the medial nucleus of the trapezoid body (MNTB), which in turn are activated by acoustic information from the contralateral ear (Finlayson and Caspary, 1989; Sanes, 1993; Kandler and Friauf, 1995). To achieve highly precise frequency-specific integration of binaural information, the synaptic arrangement between excitation and inhibition is anatomically and functionally refined during the first 3 postnatal weeks (Sanes and Friauf, 2000; Gillespie et al., 2005; Kandler et al., 2009; Case et al., 2011a; Clause et al., 2014).

Here, we demonstrate that the loss of FMRP profoundly affects this developmental synaptic rearrangement and modifies the circuitry and function of LSO neurons in adult animals. LSO neurons in young adult Fmr1 KO mice receive an excessive number of excitatory inputs, with no change in inhibitory inputs. Concomitantly, these neurons exhibit increased firing rates and altered spatial and frequency processing in response to monaural and binaural sound stimulation in vivo. These findings indicate an impaired developmental plasticity in the auditory brainstem, which might contribute to the auditory processing deficits observed in FXS.

\section{Materials and Methods}

\section{Animals}

All experiments were performed in accordance with the German animal welfare legislation and approved by the Landesamt für Gesundheit und
Soziales (Berlin). Fmr1 KO and wild-type (WT) founders were obtained from Jackson Laboratories (FVB.129P2-Pde6b + Tyrc-ch Fmrltm1Cgr/J, stock \#004624; RRID:IMSR_JAX:004624). Further crossings were done in our animal facility, and both sexes of Fmr1 KO and WT littermates were used for the experiments. Mice were housed in the animal facility before experiments, kept on a $12 \mathrm{~h}: 12 \mathrm{~h}$ light/dark cycle, and had ad libitum access to standard laboratory food pellets and drinking water.

\section{Slice preparation}

Slices were obtained from WT and Fmr1 KO mice of postnatal day 8/9 (P8), 13/14 (P14), 19-21 (P21), and P30-P35 (P33). Animals were decapitated under isoflurane anesthesia. Brains were removed in ice-cold oxygenated $\left(95 \% \mathrm{O}_{2} / 5 \% \mathrm{CO}_{2}\right)$ sucrose replacement solution (in mM as follows: $2.5 \mathrm{KCl}, 1.25 \mathrm{NaH}_{2} \mathrm{PO}_{4}, 26 \mathrm{NaHCO}_{3}, 0.5 \mathrm{CaCl}_{2}, 6 \mathrm{MgCl}_{2}, 25$ glucose, and 200 sucrose, $\mathrm{pH}$ 7.4). Transverse brainstem slices $(200 \mu \mathrm{m})$ were cut with a vibratome (VT1200S; Leica), incubated at $32^{\circ} \mathrm{C}$ for 15 min in oxygenated ACSF containing (in $\mathrm{mM}$ ) as follows: $125 \mathrm{NaCl}, 2.5$ $\mathrm{KCl}, 1.25 \mathrm{NaH}_{2} \mathrm{PO}_{4}, 26 \mathrm{NaHCO}_{3}, 2 \mathrm{CaCl}_{2}, 1 \mathrm{MgCl}_{2}$, and 25 glucose, and then maintained at room temperature. For recordings, slices were transferred to a recording chamber, which was perfused continuously with oxygenated ACSF at $32^{\circ} \mathrm{C}$ and visualized with an upright microscope (Axioscope, Carl Zeiss) using infrared-differential interference contrast optics. All reagents and drugs were purchased from Sigma-Aldrich and Biotrend unless otherwise indicated.

\section{In vitro electrophysiology}

Whole-cell current- and voltage-clamp recordings were made from visually identified LSO neurons using a Multiclamp 700B amplifier (Molecular Devices). All experiments were performed at the nearphysiological temperature of $32^{\circ} \mathrm{C}$. Patch pipettes were pulled from borosilicate glass capillaries (BioMedical Instruments) on a DMZ Universal Puller (Zeitz Instruments). When filled with electrode solution, patch pipettes had a resistance of $2-4 \mathrm{M} \Omega$.

For current-clamp recordings and HCN current measurements, the pipette solution contained the following (in $\mathrm{mm}$ ): $125 \mathrm{~K}$-gluconate, 5 $\mathrm{KCl}, 10$ HEPES, 1 EGTA, $2 \mathrm{Na}_{2} \mathrm{ATP}, 2 \mathrm{MgATP}, 0.3 \mathrm{Na}_{2} \mathrm{GTP}$, and 10 $\mathrm{Na}$-phosphocreatine, $\mathrm{pH} 7.25$, with $\mathrm{KOH}$. To record synaptic currents, patch electrodes were filled with the following (in mM): $99 \mathrm{CsMeSO}_{4}, 41$ CsCl, 10 HEPES, 10 EGTA, $2 \mathrm{Na}_{2}$ ATP, 2 MgATP, $0.3 \mathrm{Na}_{2}$ GTP, 5 TEA-Cl, $1 \mathrm{CaCl}_{2}$, and $5 \mathrm{QX} 314, \mathrm{pH} 7.25$, with $\mathrm{CsOH}$.

Stimulus generation and recordings were done with pCLAMP (version 10.2, Molecular Devices). Both voltage and current signals were low-pass filtered at $10 \mathrm{kHz}$ with a four-pole Bessel filter and sampled at a rate of $50 \mathrm{kHz}$. Traces were digitally filtered at $2 \mathrm{kHz}$.

During current-clamp experiments, the bridge-balance was adjusted to compensate for artifacts arising from electrode resistance. During voltage-clamp recordings, whole-cell capacitance was compensated and used as a measure of cell surface area. The series resistance $(<10 \mathrm{M} \Omega)$ was compensated to a residual of $2-2.5 \mathrm{M} \Omega$ and was not allowed to change $>20 \%$ during recordings.

Synaptic currents were evoked by stimulating the ascending fibers with a glass electrode filled with $2 \mathrm{M} \mathrm{NaCl}$. Stimulation electrodes were placed in the excitatory fiber bundle arising from the ventral acoustic stria or in the inhibitory fiber bundle in the medial ventral edge going to the LSO. PSCs were evoked by brief biphasic pulses (100 $\mu$ s, stimulation intensities $5-85 \mathrm{~V}$ ) triggered by an analog stimulus isolation unit (BSI-950, Dagan). EPSCs were isolated by addition of $1 \mu \mathrm{M}$ strychnine and $10 \mu \mathrm{M}$ SR95531, whereas inhibitory (I) PSCs were isolated by addition of $25 \mu \mathrm{M}$ APV-5 and $10 \mu \mathrm{M}$ DNQX. Minimal and maximal stimulation experiments were conducted as described previously (Kim and Kandler, 2003; Noh et al., 2010; Hirtz et al., 2012; Clause et al., 2014; Hirao et al., 2015). Briefly, the stimulation intensity was gradually increased in increments of $5 \mathrm{~V}$ up to $50 \mathrm{~V}$ and thereafter in increments of $10 \mathrm{~V}$ up to $85 \mathrm{~V}$. Minimal stimulation was defined as the stimulation strength $(15-25 \mathrm{~V})$ where the PSC was first measurable containing a synaptic failure in $>40 \%$. At this intensity, 100 evoked responses were recorded and the peak amplitudes were averaged excluding the failures. For maximal stimulation, intensities were increased until the peak amplitudes of synaptic responses reached a plateau $(55-65 \mathrm{~V})$. The mean of at least five consecutive pla- 
teau responses was used as the maximal synaptic input strength for a given LSO neuron.

To estimate short-term plastic changes of excitatory inputs to repetitive stimulations (50, 100, and $200 \mathrm{~Hz}, 20$ pulses, 10 repetitions), PSC amplitudes were normalized to the first amplitude. Steady-state depression was obtained by calculating the mean value of the last three normalized PSC amplitudes.

Membrane properties are shown with liquid junction potential subtraction $(-10.5 \mathrm{mV}$ for $\mathrm{CC}$ and $\mathrm{Ih}$ measurements). Input resistance was assessed from the peak hyperpolarization triggered by $-100 \mathrm{pA}$ current injection according to Ohm's law. Membrane time constants were calculated from the voltage deflection in response to $-100 \mathrm{pA}$ current injection using a single exponential fit.

HCN currents were isolated by pharmacological blockade of other ionic currents by applying the following drugs to the bath (in $\mathrm{mM}$ ) as follows: 1 3,4-diaminopyridine, 10 TEA-Cl, $0.2 \mathrm{BaCl}_{2}, 0.001$ TTX, 0.05 $\mathrm{NiCl}_{2}, 0.1 \mathrm{CdCl}_{2}, 0.01$ DNQX, 0.025 DL-AP5, and 0.001 strychnine (Baumann et al., 2013). The $\mathrm{NaCl}$ concentration was reduced to maintain iso-osmolarity. Ih was activated by applying depolarizing and hyperpolarizing voltage steps from -40.5 to $-120.5 \mathrm{mV}$. Tail currents were measured at a holding potential of $-100.5 \mathrm{mV}$ following each voltage step. Half-maximal activation of Ih was computed from tail currents. Tail current amplitudes were measured $20 \mathrm{~ms}$ after the termination of the hyperpolarizing voltage steps. These amplitudes were normalized to the maximal amplitude of each neuron. Values were fitted to a Boltzmann function to obtain the half-maximal activation voltage V1/2.

All electrophysiological data were analyzed in IGOR Pro (version 6.22, Wavemetrics) using the custom-written package Neuromatic (Jason Rothman, University College London, London) and in Clampfit (version 10.0, Molecular Devices).

\section{Immunohistochemistry}

Fifty animals (25 WT and 25 Fmrl KO) were anesthetized by an intraperitoneal injection of fentanyl (Janssen-Cilag), medetomidin (Ratiopharm), and metformin (Pfizer). They were perfused transcardially with $0.1 \mathrm{~m}$ phosphate buffer, $\mathrm{pH}$ 7.4, for $3 \mathrm{~min}$ followed by PFA (Carl Roth; $4 \%$ in $0.1 \mathrm{M}$ phosphate buffer, $\mathrm{pH} 7.4$ ) for $15 \mathrm{~min}$. Immediately after perfusion, brains were removed and postfixed overnight in $4 \% \mathrm{PFA}$ at $4^{\circ} \mathrm{C}$. Brains were thoroughly washed at room temperature with $0.1 \mathrm{M}$ PBS, $\mathrm{pH}$ 7.4. Coronal brain sections of $50 \mu \mathrm{m}$ were obtained using a vibratome (VT1200, Leica). Sections containing the LSO were collected. Unspecific binding was blocked by incubating the sections in a solution containing $10 \%$ normal donkey serum (GeneTex), 0.2\% Triton X-100 (Carl Roth), and $0.1 \mathrm{M}$ PBS, for $1 \mathrm{~h}$ at room temperature. Slices were subsequently incubated overnight in the primary antibody sera containing, depending on the experiment, rabbit $\alpha$-FMRP (Abcam; dilution 1:500, RRID:AB_2278530), rabbit $\alpha$-vGluT1 (Synaptic Systems; dilution 1:1000, RRID:AB_887875), guinea-pig $\alpha$-vGluT2 (Synaptic Systems; dilution 1:1000, RRID:AB_887884), rabbit $\alpha$-GluR1 (Millipore; dilution 1:1000, RRID:AB_2113602), chicken $\alpha$-MAP2 (Neuromics; dilution 1:1000, RRID:AB_2314763), 3\% normal donkey serum, and $0.2 \%$ Triton $\mathrm{X}-100$, in $0.1 \mathrm{M}$ PBS.

Slices were washed in $0.1 \mathrm{M}$ PBS and incubated for $2 \mathrm{~h}$ at room temperature in secondary antibody sera containing 3\% normal donkey serum, $0.2 \%$ Triton X-100, Alexa-488 donkey $\alpha$-rabbit (Invitrogen; dilution 1:250, RRID:AB_2535792), and Alexa-647 donkey $\alpha$-chicken (Dianova; dilution 1:300, RRID:AB_2340379). Negative controls were obtained by omitting the primary antibody. Sections were washed several times in $0.1 \mathrm{M}$ PBS, mounted and covered with homemade antifading mounting media (Indig et al., 1997). Fluorescent micrographs were acquired using a confocal laser scanning microscope (TCS SP8, Leica Microsystems) equipped with a $5 \times$ HCX PL FLUOTAR objective (NA $0.15), 20 \times$ HC PL APO Imm Corr objective ( $0.75 \mathrm{NA}$ ), and a $63 \times \mathrm{HCX}$ PL APO immersion-oil objective (1.4 NA). The pinhole was set to 1 Airy unit for each channel. Illumination and detection pathways were separated for each fluorophore, and individual color channels were sequentially acquired to avoid bleed-through artifacts. The acquisition settings were adjusted to cover the entire dynamic range of the detectors and remained unchanged during the course of the imaging process. $Z$ stacks of confocal images were obtained, and maximal projections of $4-6$ single optical sections were used for high-magnification figures.

For analysis by densitometry, coronal sections spanning the rostrocaudal extent of LSO (100 $\mu \mathrm{m}$ apart) were imaged using a $63 \times$ objective (NA 1.4 , voxel size $180 \mathrm{~nm})$. Stacks of confocal images were further examined with ImageJ (National Institutes of Health, RRID:SCR_003070). Thresholds for immunostaining were set based on the maximal pixel intensity of sampled negative controls. Objects exceeding the threshold detection were identified as labeled, and the mean gray level of the immunostaining and the immunostained area were measured as described previously (Rotschafer et al., 2015; Fuentes-Santamaría et al., 2016). Briefly, the mean gray level of the immunostaining was used as an indirect indicator of protein levels. For vGluT staining, we also measured the immunostained area to estimate the area occupied by excitatory synaptic endings. This was calculated as the summed area of all immunopositive objects divided by the total cross-sectional area of the LSO (Benson et al., 1997; Rotschafer et al., 2015; Fuentes-Santamaría et al., 2016).

\section{In vivo electrophysiology}

Surgery. Adult mice (52- to 96-d-old) were initially anesthetized by an intraperitoneal injection of a mixture of xylazine (Rompun $2 \%, 5 \mathrm{mg} / \mathrm{kg}$ ) and ketamine (Ketavet 10\%, $100 \mathrm{mg} / \mathrm{kg}$ ). Additional doses were given when needed. Rectal temperature was monitored and maintained at $36^{\circ} \mathrm{C}-37^{\circ} \mathrm{C}$ with a heating pad (TC01, MCS). The frontal skull was exposed, and a custom-made headpost was attached to the skull using dental cement (Charisma, Heraeus-Kulzer). A craniotomy was performed to expose the cerebellum overlying the auditory brainstem, and the covering dura was removed. Animals were placed in a sound-attenuating chamber (Desone) and fixed in a computer-controlled stereotaxic frame (Neurostar) using the mounted headpost. Cardiac function, respiration, and tentative movements of the animal were monitored via ECG, using an amplifier (P55, Grass Technologies) connected to an oscilloscope and to loudspeakers for optical and acoustical supervision.

Data acquisition. Recording electrodes were pulled from borosilicate glass capillaries (10-15 $\mathrm{M} \Omega$, BioMedical Instruments) on a PC-10 puller (Narishige) and filled with $2 \mathrm{~m} \mathrm{NaCl}$, containing 2\% HRP (Type II, Sigma-Aldrich). Neuronal activity was amplified and filtered $(300-3000 \mathrm{~Hz})$ using a Model 3000 amplifier with regular headstage (A-M Systems). Analog signals were digitized at $24.4 \mathrm{kHz}$ sampling rate and fed into a computer via an RZ6 Auditory Processor (TDT). Real-time spike data were displayed and selected using Brainware (TDT), according to manually adjusted criteria, to ensure that the analyzed data originated from a single neuron. To verify the exact location of the recording sites, stereotaxic coordinates for every recorded neuron were logged; and toward the end of each session, the recording site of one LSO neuron was labeled with an injection of HRP via administration of a $90 \mathrm{~V}$ DC current for 3 min using a stimulus isolation unit (ISO-STIM 01D, npi electronic). At the end of each experiment, animals were given a lethal dose of ketamine and xylazine, the brain was dissected out and immersion fixed in 4\% PFA overnight. HRP injections were visualized by cutting the fixed tissue in $70 \mu \mathrm{m}$ sections (VT1200, Leica Microsystems), applying a diaminobenzidine reaction (DAB kit, Sigma-Aldrich) and a Nissl counterstain. All injection sites were located within the area of the LSO, matching the reconstruction of stored stereotaxic coordinates.

Acoustic stimulation. Sound stimuli were designed using the Real-Time Processor Visual Design Studio (RPvdsEx; TDT); sequence and parameters of sounds were controlled with Brainware. Stimulus generation was performed with a $195.3 \mathrm{kHz}$ sampling rate using the digital signalprocessing hardware of the RZ6. Signals were delivered via MF1 magnetic speakers (TDT) in closed field configuration, with connected plastic tubing inserted into the animal's pinnae. Acoustic signals were calibrated using a $1 / 4$ inch measurement microphone (40BF, G.R.A.S.), customwritten MATLAB software (The MathWorks), and SigCalRP calibration software (TDT).

A neuron was considered an LSO principal cell when it responded to both white noise stimuli and tone bursts, and was exclusively ipsilaterally driven and inhibited by contralateral stimulation. After isolation of single-unit activity, the neuron's spontaneous firing rate was recorded. A tuning curve was performed using ipsilaterally presented pure tone 
A

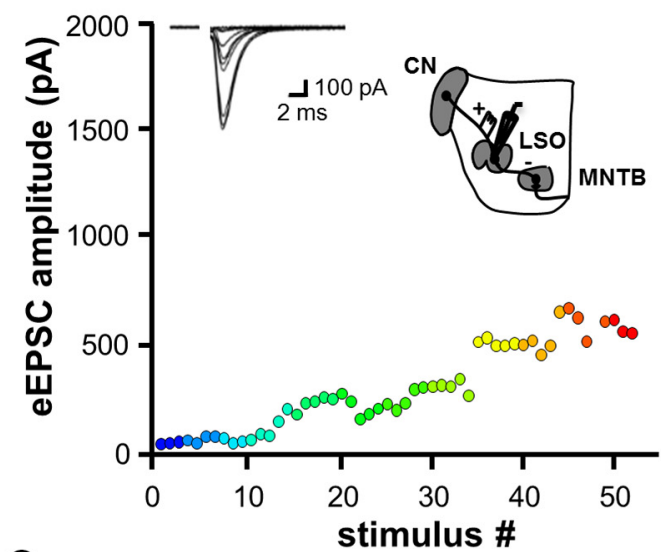

C

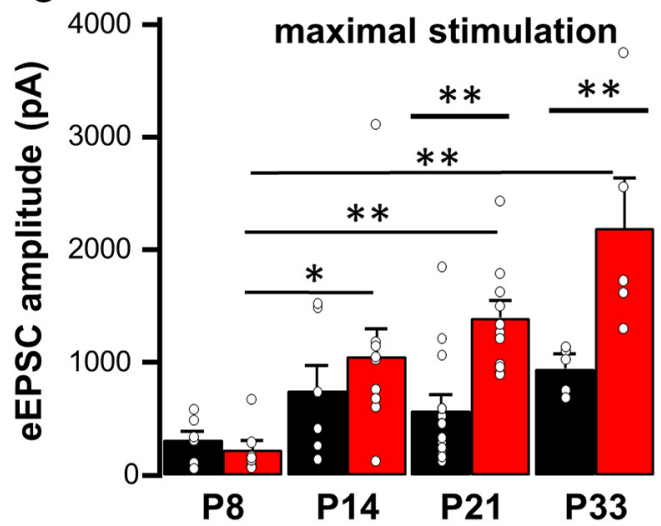

B

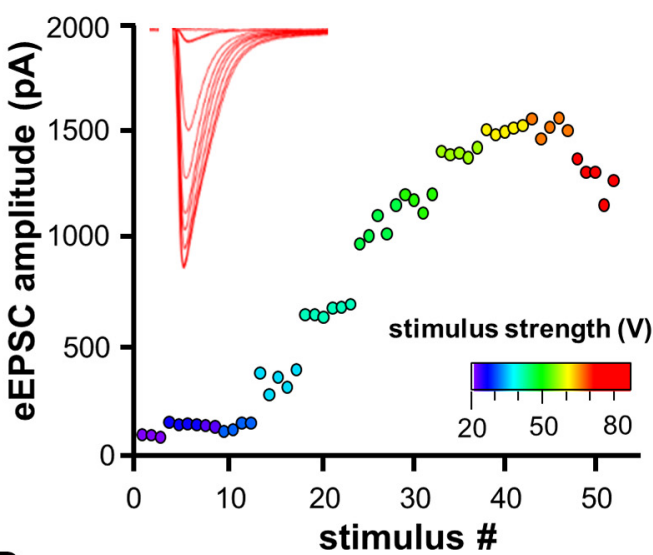

D

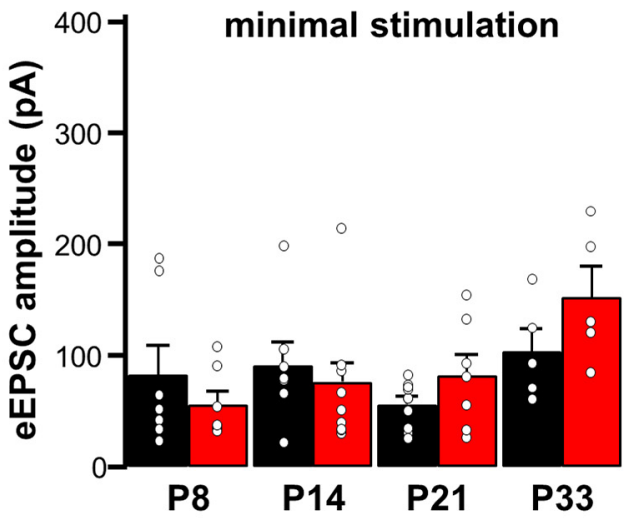

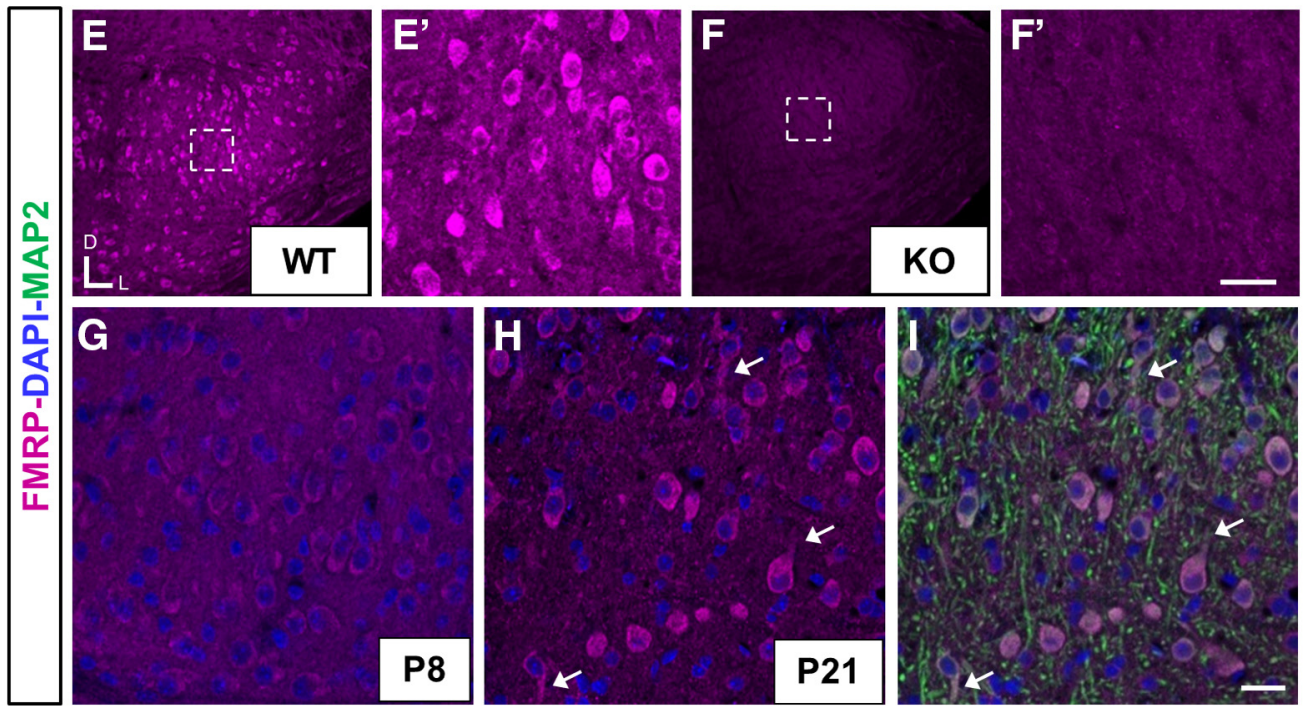

Figure 1. Developmental strengthening of the VCN-LSO pathway is enhanced in Fmr $1 \mathrm{KO}$ mice. Sample input- output curves in WT ( $\boldsymbol{A}$, in black here and throughout) and Fmr $1 \mathrm{KO}$ mice ( $\boldsymbol{B}$, in red here and throughout) reveal an impaired development of the VCN-LSO connections in Fmr1 KO mice at the end of the third postnatal week. $\boldsymbol{A}$, Inset, Schematic of the performed experiment. Summary data show evoked EPSC (eEPSC) amplitudes in response to maximal ( $\boldsymbol{C}$ ) and minimal (D) stimulation of the ipsilateral, excitatory fibers in the developing LSO. $\boldsymbol{E}-\boldsymbol{I}$, Confocal images display an enrichment of FMRP over development of the $L S O$ neurons. $E$, $F$, Validation of the antibody against FMRP in sections including $L S 0$. Dashed squares indicate where the high-power images were taken. $\mathbf{G}-\mathbf{I}$, Somata and proximal processes (white arrows) of LSO neurons are strongly FMRP-immunoreactive between P8 and P21. Blue represents DAPI staining. Magenta represents FMRP staining. Green represents MAP2 staining. Scale bars: $\boldsymbol{E}, \boldsymbol{F}, 100 \mu \mathrm{m} ; \boldsymbol{E}^{\prime}, \boldsymbol{F}^{\prime}, 50 \mu \mathrm{m} ; \boldsymbol{G}, \boldsymbol{H}, \mathbf{I}, 20 \mu \mathrm{m}$. Bar graphs represent mean \pm SEM. $p<0.05$ was considered statistically significant. ${ }^{*} p<0.05$ (two-way ANOVA followed by Bonferroni post tests). ${ }^{* *} p<0.01$ (two-way ANOVA followed by Bonferroni post tests).

bursts ( $100 \mathrm{~ms}$ duration, $5 \mathrm{~ms}$ rise/fall time, $0-90 \mathrm{~dB}$ SPL) to determine the neuron's frequency response area, its characteristic frequency (CF; frequency at which threshold is lowest), and intensity threshold. First spike latency and firing pattern were measured at CF, $20 \mathrm{~dB}$ above threshold. An ILD function was recorded using tone bursts (100 ms duration, $5 \mathrm{~ms}$ rise/fall time) at the neuron's CF, keeping the ipsilateral stimulus intensity constant at $20 \mathrm{~dB}$ above threshold and varying the contralateral intensity by steps of $5 \mathrm{~dB}$ ( 10 repetitions for each combination).

Data analysis. Analysis of recorded data was performed in MATLAB (RRID:SCR_001622) and Prism version 5.01 (GraphPad Software, RRID:SCR_002798). To describe a cell's response to ILDs, a sigmoid function was fit to the data using the following formula: 


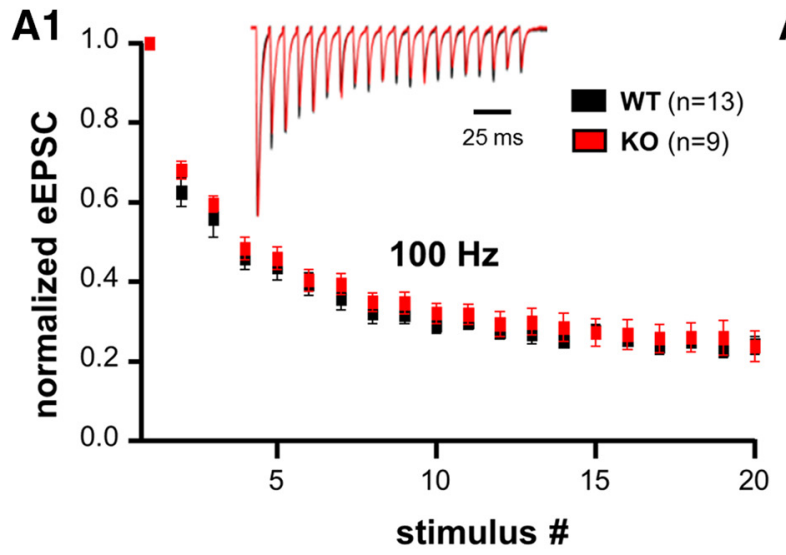

B
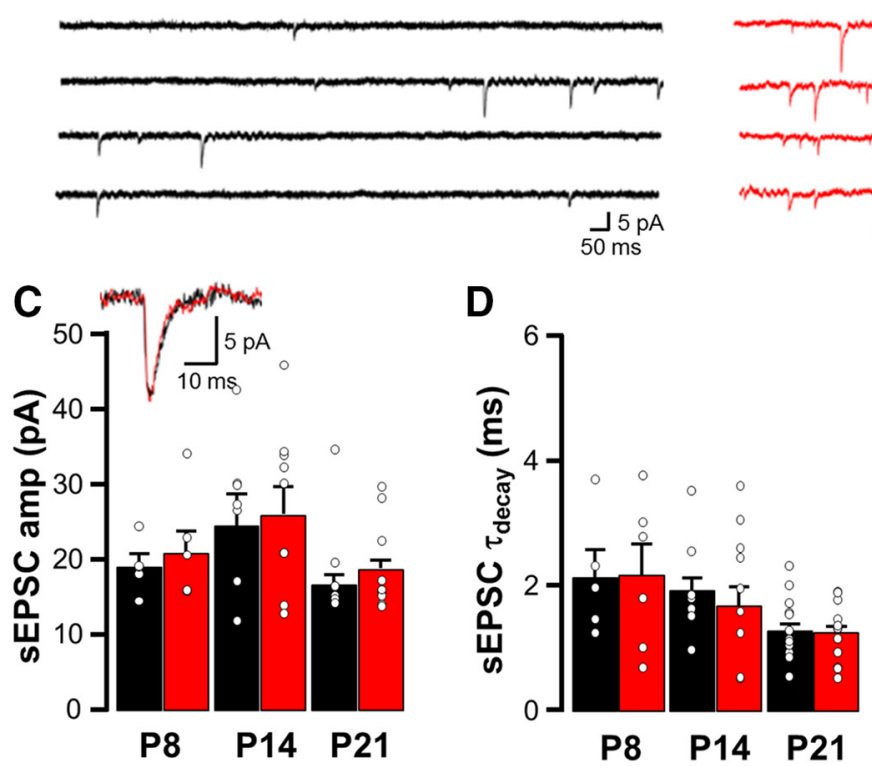

A2

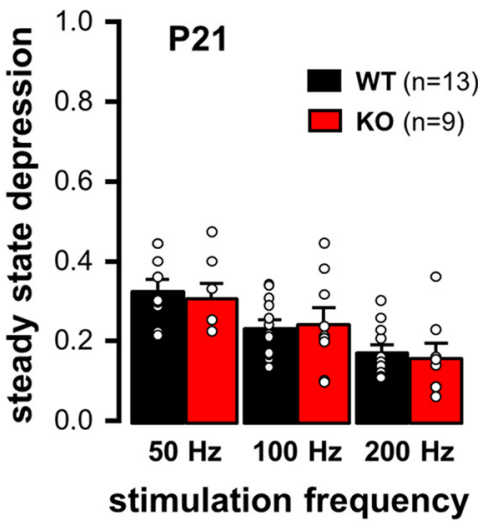

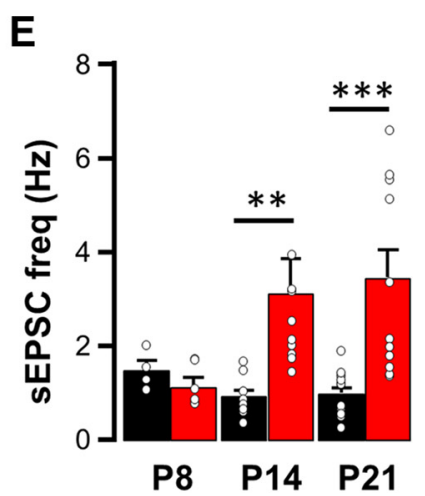

Figure 2. Increase in the number of release sites underlies the elevated EPSC amplitudes in Fmr $1 \mathrm{KO}$ mice. A1, Averaged eEPSC amplitudes in response to a $100 \mathrm{~Hz}$ stimulus (20 repetitions) for WT and Fmr1 KO mice. $\boldsymbol{A 2}$, Steady-state depression of eEPSCS remains unchanged for various stimulation frequencies. $\boldsymbol{B}-\boldsymbol{E}$, Analysis of the sEPSCs reveals unaffected amplitudes and decay time constants $(\boldsymbol{C}, \boldsymbol{D})$, yet increased frequency $(\boldsymbol{E})$ comparing WT and Fmr $1 \mathrm{KO}$ mice. This indicates an increase in the number of release sites without a change in the quantal size. Bar graph represents mean \pm SEM. ${ }^{* *} p<0.01$ (two-way ANOVA followed by Bonferroni post tests). ${ }^{* * *} p<0.001$ (two-way ANOVA followed by Bonferroni post tests).

$$
\mathrm{y}=\mathrm{a}+\frac{\mathrm{b}}{1+\exp \left(-\frac{\mathrm{h}-\mathrm{x}}{\mathrm{s}}\right)}
$$

where $y$ is the discharge rate, $x$ is the ILD, $h$ is the ILD of the half-maximal inhibition (point of inflection), $s$ is the slope at the point of inflection, and $a$ and $b$ are free parameters. Increasing values of the half-maximal inhibition ILD reflect a shift of the ILD toward the ipsilateral ear (i.e., higher contralateral sound intensity is needed to achieve an inhibitory effect).

As a measure of tuning sharpness, the $Q$ values for each neuron were determined. The Q10 value is calculated as the ratio of CF over the bandwidth $10 \mathrm{~dB}$ above threshold, whereas the Q30 value is $30 \mathrm{~dB}$ above threshold. A larger $Q$ value reflects a sharper tuning (i.e., a more narrow frequency response area).

\section{Experimental design and statistical analysis}

Data for all experiments were sampled from Fmrl KO animals and their WT littermates from both sexes. In all cases, 3 or more animals of the same genotype and age were used for each parameter. Individual sample sizes for in vitro and in vivo electrophysiological experiments $(n=$ number of neurons) are reported separately for each experiment. For immunohistochemical experiments, $N$ values (number of animals) are reported. Statistical analyses were conducted with GraphPad Prism soft- ware. One-way or two-way ANOVA was used for comparing age or age and genotype. Post hoc Bonferroni or Dunnett's pairwise comparisons were performed when significant effects for genotype were found by two-way ANOVA. Differences between two means were assessed with the unpaired two-tailed Student's $t$ test for normally distributed data and with Mann-Whitney Test for pairwise comparison of nonparametrically distributed data. Data are mean \pm SEM.

\section{Results}

Developmental strengthening of the VCN-LSO pathway is enhanced in the Fragile X mouse model (Fmr1 KO)

Hyperexcitability of neural circuits can be caused by unbalanced excitatory and inhibitory inputs or derive from elevated intrinsic membrane excitability. To investigate whether the auditory hypersensitivity observed in FXS is caused by an aberrant development of excitatory synaptic inputs in auditory brainstem neurons, we examined the functional development of the ventral cochlear nucleus-LSO (VCN-LSO) circuit in the mouse model of FXS. Using minimal and maximal stimulation techniques in acute brainstem slices prepared from 8- to 21-day old mice, we evaluated the developmental excitatory input strength of a sin- 
gle VCN axon (minimal response) and of all VCN axons (maximal response) converging onto one LSO neuron (Noh et al., 2010; Case et al., 2011a; Hirao et al., 2015). In P21 mice, the amplitude of evoked EPSCs increased in discrete steps in response to a gradual rise in stimulus intensity in both genotypes. However, in Fmr1 KO mice, the maximal response amplitudes were considerably larger compared with the Fmrl WT mice (Fig. $1 A, B)$. In Fmr1 KO mice, the maximal input strength increased $>5$-fold during the first 3 postnatal weeks (P8: $228 \pm 78.9 \mathrm{pA}$, $n=7, \mathrm{P} 14: 1061 \pm 242.5 \mathrm{pA}, n=11, \mathrm{P} 21:$ $1396 \pm 149.3 \mathrm{pA}, n=11, \mathrm{P} 33: 2195 \pm 988$ $\mathrm{pA}, n=5$ ) (two-way ANOVA with post hoc Dunnett's test P8 vs P14 ( $q=3.1), \mathrm{P} 21$ $(q=4.4)$, P33 $(q=6.1)$; all $p<0.01, \mathrm{df}=$ 58) (Fig. 1C). In contrast, in Fmrl WT littermates, the developmental strengthening was much smaller and did not increase after P14 (P8: $318.3 \pm 70.45 \mathrm{pA}$, $n=7 ; \mathrm{P} 14: 758.8 \pm 210.8 \mathrm{pA}, n=7, \mathrm{P} 21$ : $582 \pm 129.8 \mathrm{pA}, n=14$, P33: $945 \pm 207$ pA, $n=5$ ) (two-way ANOVA with post hoc Dunnett's test P8 vs P14, P21, P33, for all $p>0.05, q<2$, df $=58$ ). KO animals showed significantly larger maximal EPSC amplitudes at P21 and P33 (two-way ANOVA; $p<0.0001$; WT vs KO P21: $p=$ $0.0019, t=3.7$; P33: $p=0.0024, t=6.2$, $\mathrm{df}=58)$. In contrast, single-fiber strength (min EPSC), measured by minimal stimulation techniques, remained largely unaffected in Fmrl KO mice (Fig. 1D) (P8 WT $83 \pm 26 \mathrm{pA}, n=7$ vs P8 KO $56 \pm 12$ $\mathrm{pA}, n=7$; P14 WT $93 \pm 30 \mathrm{pA} n=7$ vs $\mathrm{P} 14 \mathrm{KO} 77 \pm 17 \mathrm{pA}, n=11$; P21 WT $57 \pm$ $6 \mathrm{pA}, n=11$ vs $\mathrm{P} 21 \mathrm{KO} 83 \pm 18, n=7 ; \mathrm{P} 33$ WT $103 \pm 44, n=5$ vs P33 KO $131 \pm 41, n=$ $5 ; p>0.99, t<2, \mathrm{df}=52$ for all ages; two-way ANOVA for all ages). Together, these findings reveal an impaired development of the VCNLSO connections in the Fmrl KO mice between the second and third postnatal week.

We next explored whether this developmental change was correlated with FMRP expression levels using FMRP immunostaining at different developmental periods in the LSO. Antibody specificity against FMRP was verified in Fmr1 KO mice $(n=$ 2) (Fig. $1 E, F)$. Between $\mathrm{P} 8(N=2)$ and $\mathrm{P} 21$ $(N=2)$, LSO neurons of Fmrl WT mice showed a developmental enrichment of FMRP immunostaining mostly in the somata and proximal processes (Fig. 1G-I). This delayed developmental expression of FMRP correlates with the observed time course of excessive synaptic strengthening.

Increased synapse number underlies the enhanced excitatory strength in LSO neurons of FXS

The synaptic mechanisms underlying the enhanced strength of the VCN-LSO fibers in FXS mice can be a function of an increase
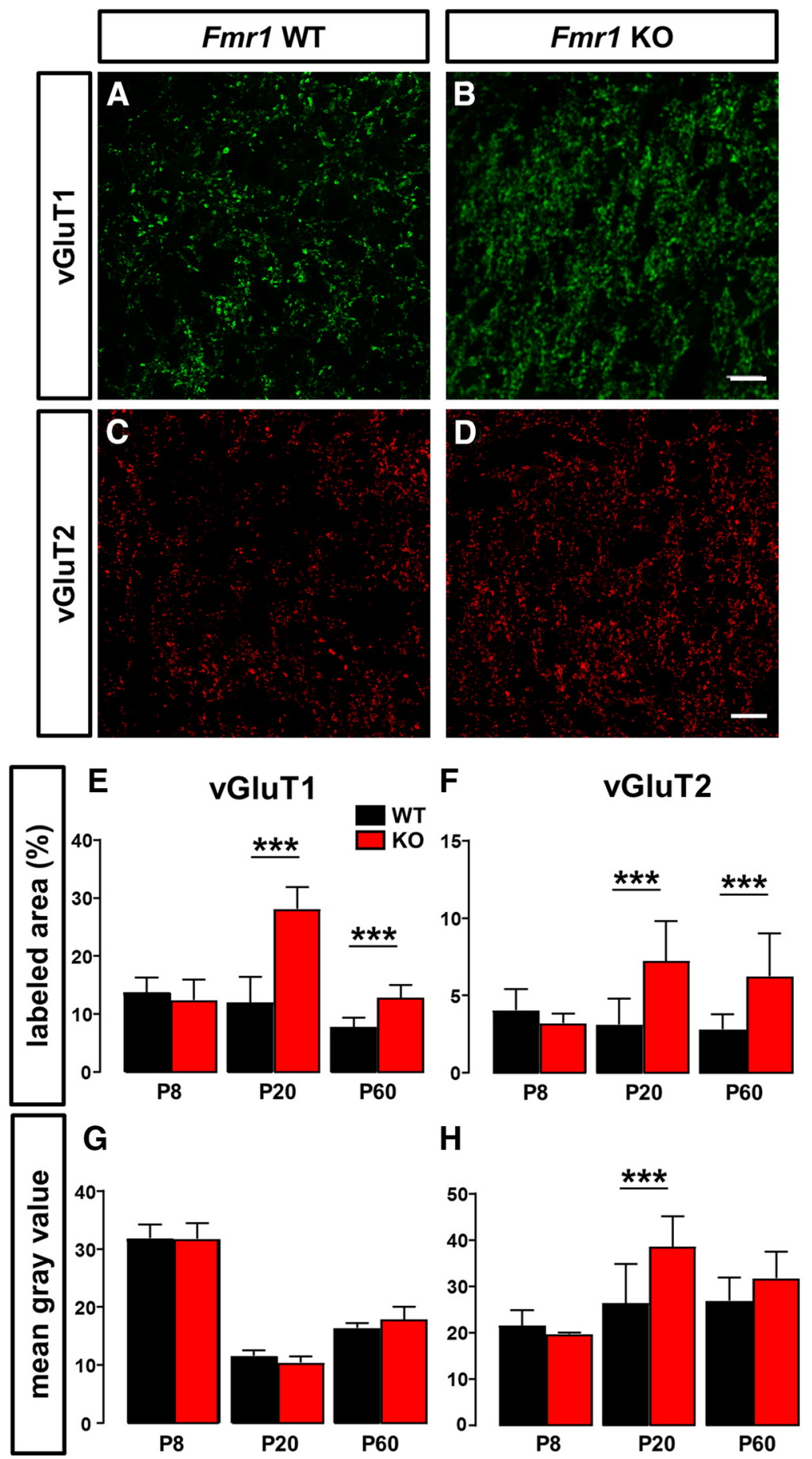

Figure 3. Increased vGluT1/2 immunostained area in Fmr $1 \mathrm{KO}$ LSO neurons. A-D, Micrographs of WT and Fmr $1 \mathrm{KO}$ LSO sections immunostained against vGluT1 (green) and vGluT2 (red) at P20. $\boldsymbol{E}-\boldsymbol{H}$, Quantification of vGluT1/2 signal intensities $(\boldsymbol{E}, \boldsymbol{F})$ and immunolabeled area $(\boldsymbol{G}, \boldsymbol{H})$ of $L S 0$ coronal sections on P8, P20, and P60 WT and Fmr 1 KO mice. Data are mean \pm SEM. Scale bars: $20 \mu \mathrm{m} .{ }^{* * *} p<0.001$ (two-way ANOVA followed by Bonferroni post tests).

in the probability of vesicle release, quantal amplitude, or the number of functional release sites. To investigate the first possibility, we measured short-term depression in $13 \mathrm{WT}$ and $9 \mathrm{KO}$ LSO neurons (from $6 \mathrm{WT}$ animals and $5 \mathrm{KO}$ animals) in response to train stimuli at various frequencies. In P21 mice, the steadystate depression remained unchanged in both genotypes for all frequencies, arguing against an increased probability of release as the underlying mechanism ( $50 \mathrm{~Hz}$ : WT $0.33 \pm 0.026, n=10$; KO $0.32 \pm 0.036, n=9 ; 100 \mathrm{~Hz}$ : WT $0.24 \pm 0.019, n=13 ; \mathrm{KO} 0.25 \pm$ 


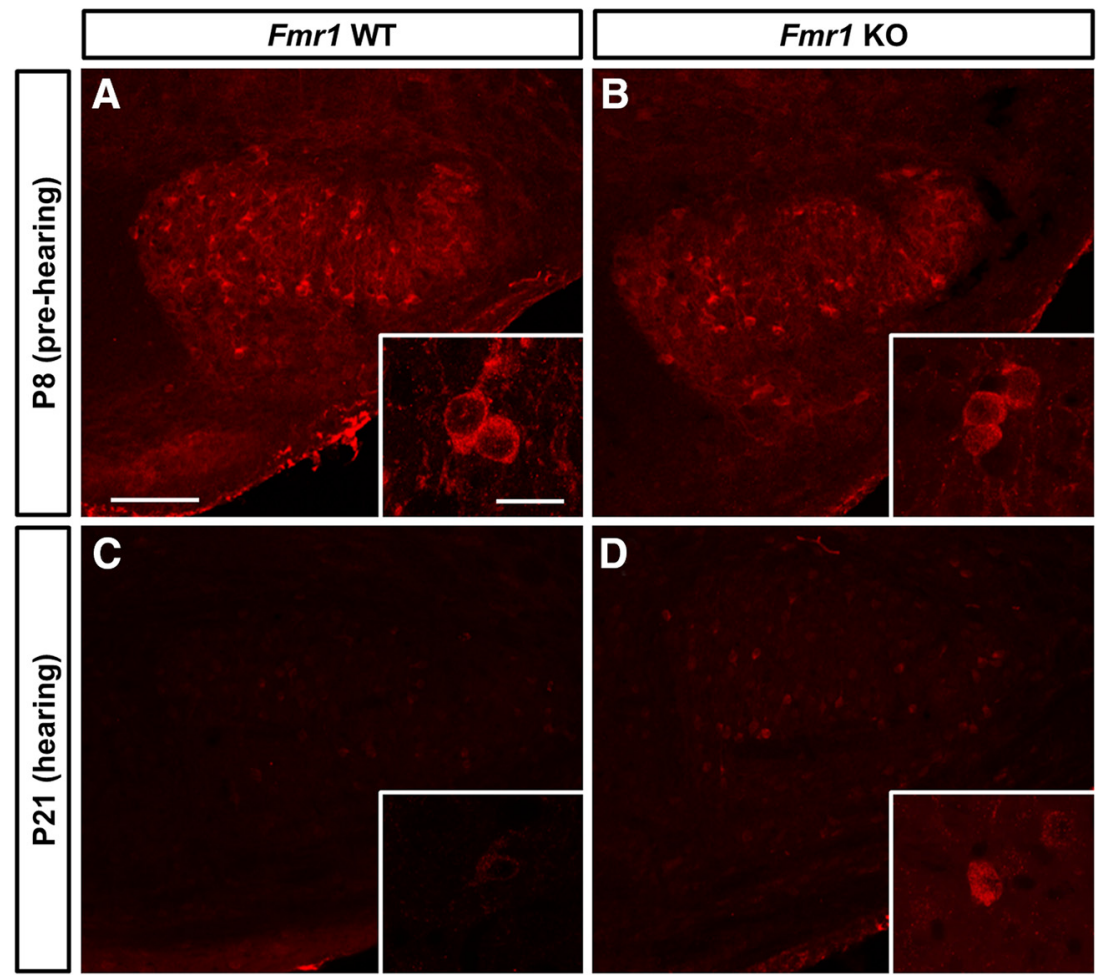

$\mathbf{E}$

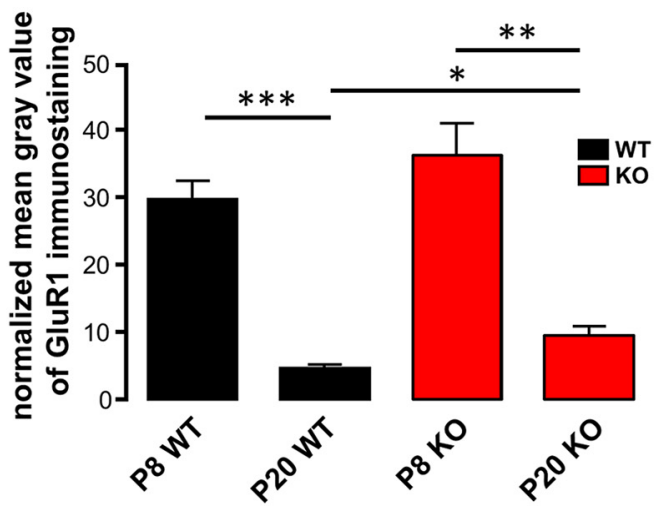

Figure 4. Developmental decrease in GluR1 immunostaining is diminished in Fmr1 KO LSO neurons. A-D, Micrographs of WT and Fmr $1 \mathrm{KO}$ immunostained against GluR1 at prehearing and hearing stages. $\boldsymbol{E}$, Quantification of GluR1 signal intensities from LSO coronal sections on 3 WT and 3 Fmr1 KO mice. Data are mean \pm SEM. Unpaired $t$ test, with or without Welch's correction, or Mann-Whitney test was used accordingly to evaluate differences between genotypes and age groups. $p<0.05$ was considered statistically significant. ${ }^{*} p<0.05,{ }^{* *} p<0.01,{ }^{* * *} p<0.001$. Scale bars: $100 \mu \mathrm{m}$; Insets, $20 \mu \mathrm{m}$.

0.039, $n=9 ; 200 \mathrm{~Hz}: 0.18 \pm 0.017, n=12 ; \mathrm{KO} 0.17 \pm 0.034, n=$ $8 ; p=0.66, F=0.27, \mathrm{df}=55$, two-way ANOVA) (Fig. $2 A$ ). Similarly, spontaneous excitatory current (sEPSC) analyses revealed unchanged amplitudes (P8: WT $19 \pm 2 \mathrm{pA}, n=5$ vs KO $21 \pm 3$ pA, $n=6$; P14: WT $25 \pm 3$ pA, $n=11$ vs KO $28 \pm 4$ pA, $n=9$; P21: WT $17 \pm 1 \mathrm{pA}, n=15$ vs KO $19 \pm 1 \mathrm{pA}, n=16$; WT vs KO P8, P14, P21: $p>0.99, F=1.4, \mathrm{df}=56$; two-way ANOVA) and decay time constants (P8: WT $2.1 \pm 0.4 \mathrm{~ms}$; KO $2.2 \pm 0.5 \mathrm{~ms}$; P14: WT $1.9 \pm 0.2 \mathrm{~ms}$ vs KO $1.9 \pm 0.3 \mathrm{~ms} ; \mathrm{P} 21$ : WT $1.3 \pm 0.1 \mathrm{~ms}$, KO $1.3 \pm 0.1 \mathrm{~ms} ; p>0.99, F=0.01, \mathrm{df}=59$ two-way ANOVA) between genotypes (Fig. $2 B-D$ ). This result, together with the lack of changes observed in single fiber strength, exclude the possibility that elevated quantal amplitude is the underlying mechanism. In contrast, we found that the frequency of sEPSC is considerably higher in LSO neurons of the FXS mice starting after hearing onset (P8: WT $1.5 \pm 0.2 \mathrm{~Hz}$ vs $\mathrm{KO} 1.16 \pm 0.2 \mathrm{~Hz} ; p>$
$0.99, t=0.4 ; \mathrm{P} 14$ : WT $0.95 \pm 0.13 \mathrm{~Hz}$ vs $\mathrm{KO} 3.18 \pm 0.7 \mathrm{~Hz} ; p=0.008, t=3.2 ; \mathrm{P} 21$ : WT $1.04 \pm 0.12$ vs KO $3.5 \pm 0.6 \mathrm{~Hz} ; p<$ $0.001, t=4.3, \mathrm{df}=55$; two-way ANOVA with post hoc comparison) (Fig. $2 E$ ). Together, these findings suggest an elevated number of release sites as the mechanism for the heightened excitatory transmission.

To confirm this finding, we additionally characterized excitatory projections to LSO neurons morphologically. To this end, we used immunolabeling of the vesicular glutamate transporters 1 and 2 (vGluT1/2) as markers of the excitatory terminals in LSO (Gillespie et al., 2005). The mean gray value was used as a measure of the protein level and the percentage of the immunolabeled area as a measure of the input area occupied by excitatory endings (Rotschafer et al., 2015; Fuentes-Santamaría et al., 2016) (Fig. 3). At the end of the third postnatal week, but not before hearing onset, FXS mice showed an increase in the immunolabeled area of both vGluT1 (P8 WT 13.76 \pm 1.15 vs KO $12.4 \pm 1.55, p>0.99, t=0.7$, both $N=3$; P20 WT $12.02 \pm 1.57$ vs $\mathrm{KO}$ $28.05 \pm 1.4, p<0.001, t=10.7$, both $N=$ 4; P60 WT $7.57 \pm 0.5$ vs KO $12.82 \pm 0.7$, $p<0.001, t=4.1, \mathrm{df}=46$ both $N=6$, two-way ANOVA with post hoc comparison) and vGluT2 (P8: WT $3.96 \pm 0.84$ vs $\mathrm{KO} 3.19 \pm 0.56, p>0.99, t=0.7$, both $N=3$; P20: WT $3.13 \pm 0.5$ vs KO $7.17 \pm$ $0.13, p<0.001, t=5$, both $N=4$, P60: WT $2.78 \pm 0.3$ vs $\mathrm{KO} 6.20 \pm 0.8, p<$ $0.001, t=4.2, \mathrm{df}=54$, both $N=6$, twoway ANOVA with post hoc comparison), which was maintained until adulthood (Fig. $3 E, F$ ). In contrast, the mean gray value remained largely unaltered for all developmental stages (vGluT1: P8 WT $31.86 \pm 1.06$ vs $\mathrm{KO} 31.8 \pm 1.19, p>0.99$, $t=0.1$, both $N=3$; P20 WT $11.56 \pm 0.3$ vs $\mathrm{KO} 10.57 \pm 0.4, p=0.5, t=2.1$, both $N=4 ; \mathrm{P} 60$ WT $16.14 \pm 0.2$ vs KO $17.17 \pm$ $0.6, p=0.11, t=2.1$, both $N=6, \mathrm{df}=46$; vGluT2: P8 WT $21.49 \pm 3.39$ vs KO $19.65 \pm 3.03, p>0.99, t=$ 0.5 , both $N=3$; P20 WT $32.58 \pm 2.5$ vs KO $39.6 \pm 1.9, p=0.001$, $t=4.1$, both $N=4$; P60 WT $26.27 \pm 1.5$ vs KO $28.33 \pm 1.7$, both $N=6, p=0.92, t=1.9, \mathrm{df}=54$; two-way ANOVA with post hoc comparison) (Fig. 3G,H). These data suggest an increase in excitatory input number but no change in expression levels of the vesicular transporters in FXS mice. Together, these findings indicate an impaired development of LSO inputs in FXS mice, leading to an excess in excitatory transmission.

\section{Developmental loss of GluR1 immunostaining is reduced in LSO neurons of FXS}

Glutamate postsynaptic receptors are developmentally regulated in the LSO. Before hearing onset, they are mainly composed of the glutamate receptor 1 (GluR1) subunit. After hearing onset, GluR1 is gradually replaced by the glutamate receptor 4 (GluR4) subunit 
A
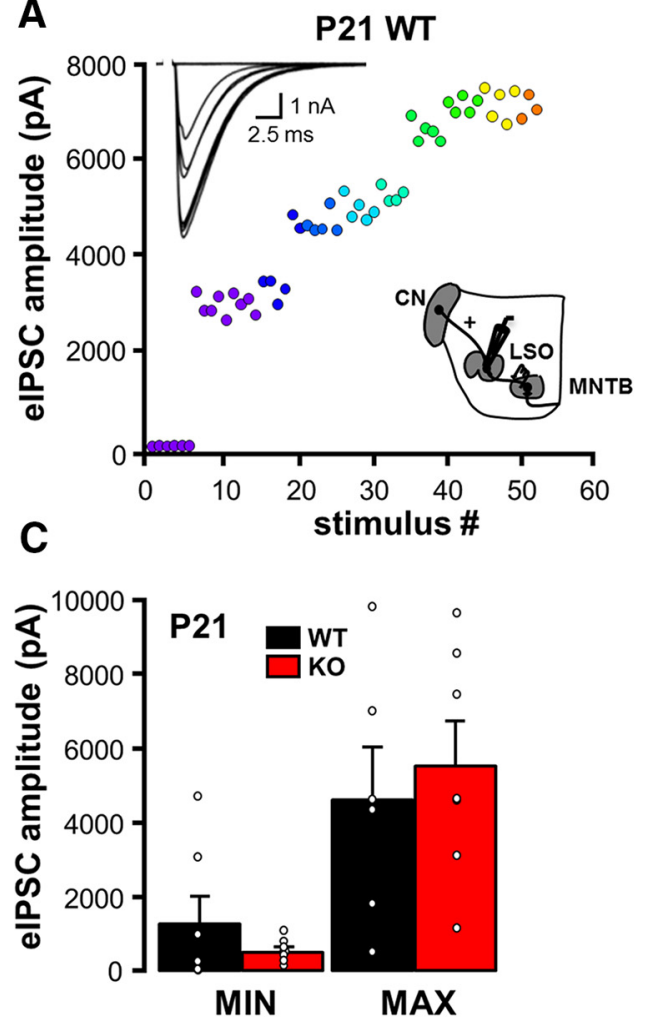

B
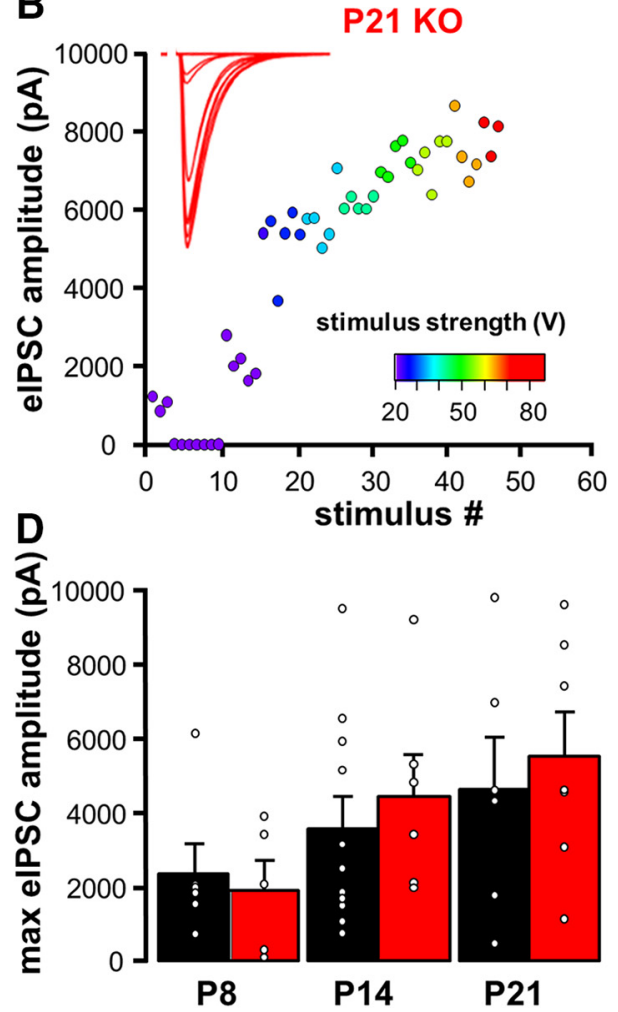

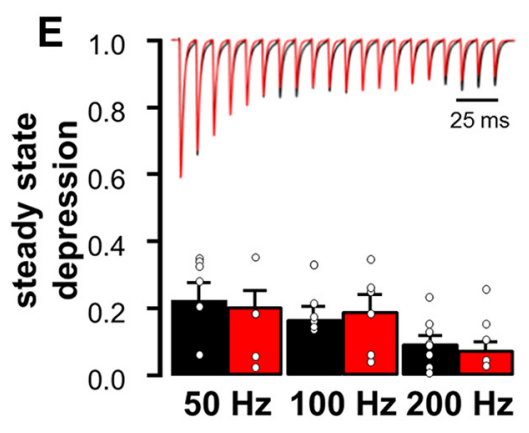

F2

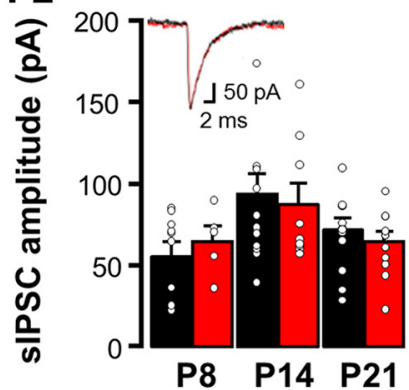

F3

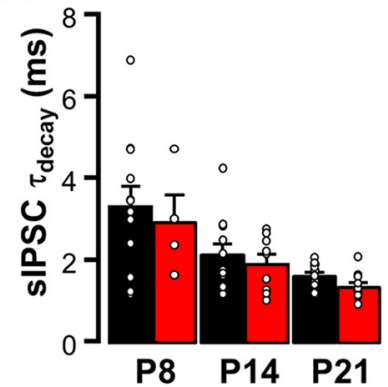

F1

P14

P14

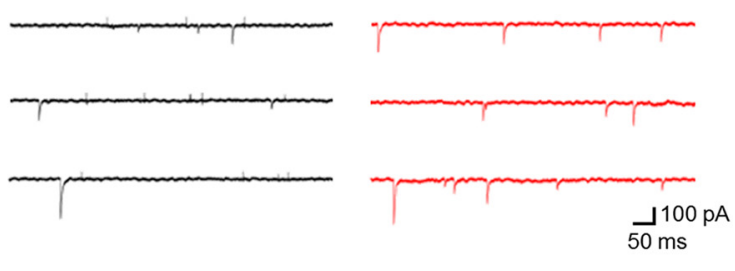

F4

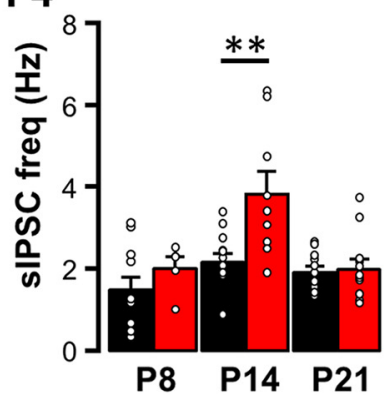

Figure 5. Inhibitory input properties of the MNTB-LSO pathway remain largely unaffected in the $F m r 1$ KO mice. Sample input- output curves in WT $(\boldsymbol{A})$ and $F m r 1 \mathrm{KO}$ mice $(\boldsymbol{B})$ reveal an unchanged synaptic strength of the MNTB-LSO connections in the Fmr $1 \mathrm{KO}$ at the end of the third postnatal week. C, Summary data show evoked IPSC (eIPSC) amplitudes in response to minimal and maximal stimulation at P21. D, Maximal input strength of elPSCs over development did not differ between genotypes. E, Steady-state depression remains unaltered in response to various stimulation frequencies. $\boldsymbol{F}$, Analysis of spontaneous IPSCS (SIPSC) (F1) reveals unaffected amplitudes (F2) and decay time constants (F3). Only at P14, there was a significant increase in the frequency of sIPSCS (F4). Bar graphs represent mean \pm SEM. $p<0.05$ was considered statistically significant. ${ }^{* *} p<0.01$ (two-way ANOVA followed by Bonferroni post tests).

(Caicedo and Eybalin, 1999; Schwartz and Eager, 1999). To find out whether this developmental replacement of GluR subunit composition is impaired in the FXS, we investigated the development of the GluR1 subunit distribution using immunostaining (Fig. 4). As expected, normalized gray values of GluR1 signal in WT mice drastically decline by $>80 \%$ between P8 and P21 (P8: $29.7 \pm 2.7, N=5$;
P21: $4.6 \pm 1.4, N=7 ; p<0.001, t=9, \mathrm{df}=4$; unpaired $t$ test with Welch's correction) (Fig. $4 A, C, E)$. In $\mathrm{KO}$ mice, we also noticed a significant reduction of the GluR1 signal by $74 \%$ during the same developmental period (P8:36.25 $\pm 4.6, N=4 ; \mathrm{P} 21: 9.48 \pm 1.36, N=$ 6; $p<0.001$, Mann-Whitney test) (Fig. $4 B, D, E$ ). However, this residual GluR1 immunostaining at P21 was significantly enhanced 
A
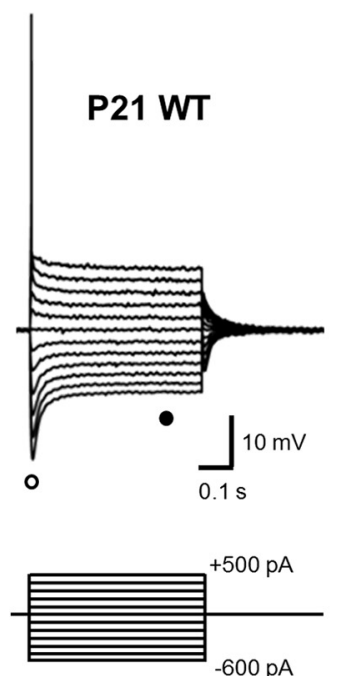

B

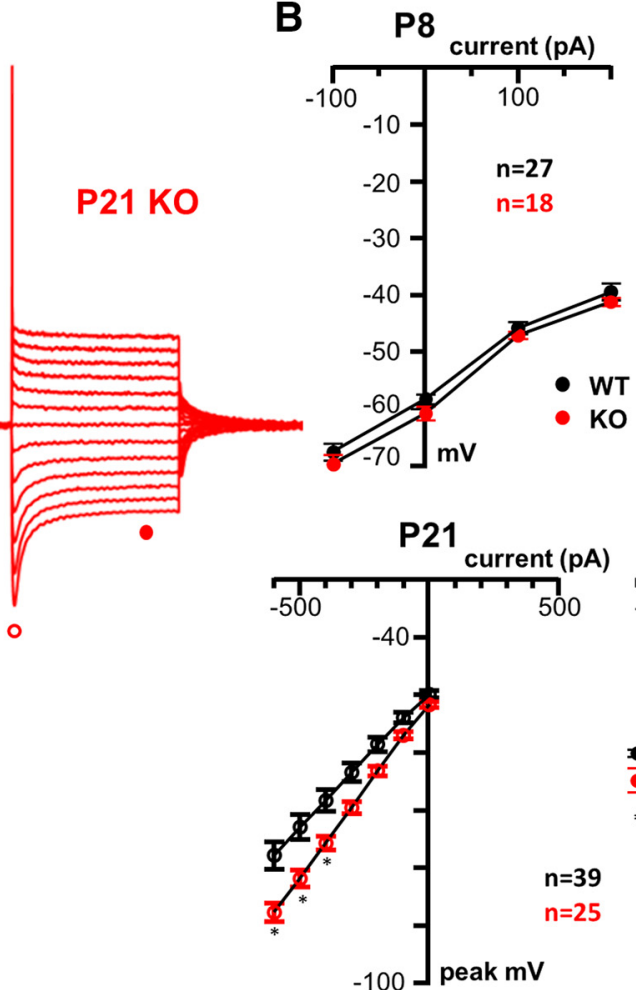

P14

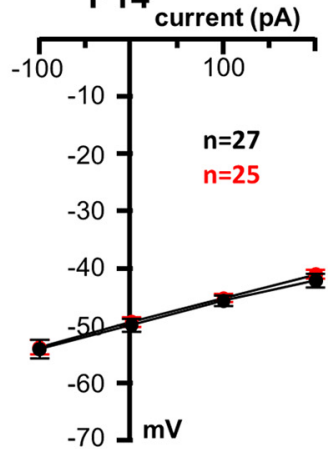

P21

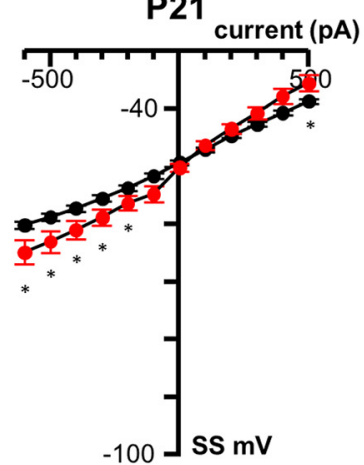

C

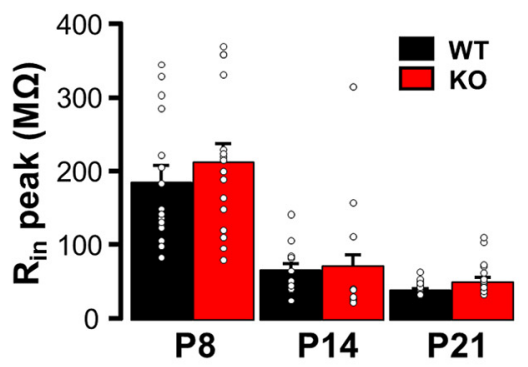

D

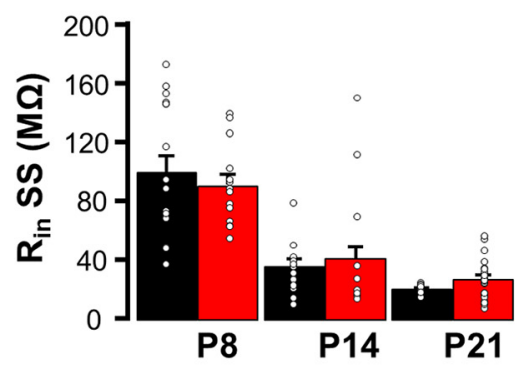

E

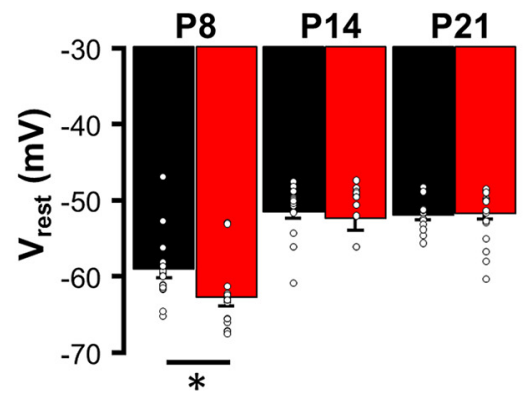

$\mathbf{F}$

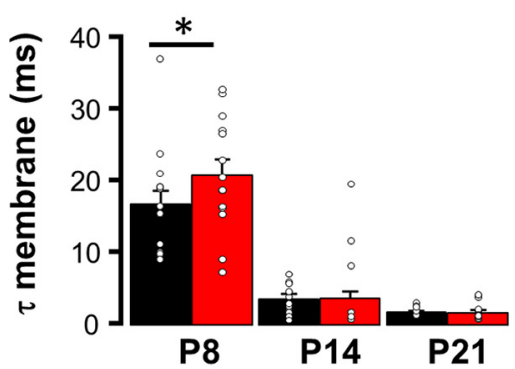

Figure 6. Input resistance is slightly enhanced in the hyperpolarizing range in $F m r 1 \mathrm{KO}$ mice, whereas other passive membrane properties are unaffected. $\boldsymbol{A}$, Sample membrane voltage responses to hyperpolarizing and depolarizing current injections from LSO neurons of WT and Fmr $1 \mathrm{KO}$ mice at P21. Negative current injections generated a slightly more hyperpolarized membrane potential in the Fmr $1 \mathrm{KO}$ mice. $\boldsymbol{B}$, Current-voltage relationships in the developing $\mathrm{LSO}$ neurons reveal no differences between genotypes during the first two postnatal weeks, whereas in P21 Fmr $1 \mathrm{KO}$ mice a modest increase in voltage deflection was found. Closed circles represent steady state. Open circles represent peak. $\boldsymbol{C}, \boldsymbol{D}$, Concomitantly, input resistance in the peak and steady state differed only at P21. $E, F$, Resting membrane potential and membrane time constant remained largely unaffected. Bar graphs represent mean \pm SEM. ${ }^{*} p<0.05$ (two-way ANOVA followed by Bonferroni post tests).

in Fmr1 KO mice (P21 WT vs P21 KO $p=0.0047$, both $N=6$, Mann-Whitney test) (Fig. 4E), which suggests an abnormal maturation of the GluR composition in FXS.

Synaptic development of the inhibitory MNTB-LSO connection is largely unaffected

In the LSO, excitatory inputs from the VCN converge with inhibitory inputs from the MNTB in a tonotopically organized manner
(Sanes, 1993; Kandler and Friauf, 1995). The inhibitory MNTBLSO pathway undergoes a neurotransmitter phenotype shift before hearing onset, from being initially GABAergic and glutamatergic to becoming primarily glycinergic (Kotak et al., 1998; Nabekura et al., 2004; Gillespie et al., 2005). Moreover, GABAspillover from presynaptic MNTB axons persists beyond hearing onset (Weisz et al., 2016). Because GABAergic transmission is affected in multiple brain areas of the Fmrl KO mice (Selby et al., 
2007; Curia et al., 2009; Olmos-Serrano et al., 2010; Braat and Kooy, 2015), we explored whether, in addition to the enhanced excitation, inhibitory transmission from the MNTB was also altered by the loss of FMRP. Surprisingly, the MNTB-LSO synaptic strength remained unaltered at any developmental age studied (Fig. 5A-D) (developmental effect: Fmr1 KO $p=0.09$, one-way ANOVA, WT 0.56, Kruskal-Wallis test). As a consequence, IPSC amplitudes did not differ between WT and $\mathrm{KO}$ animals at P21 (WT vs Fmr1 KO at P21, $4.6 \pm 1.4 \mathrm{nA}, n=6$ vs $5.6 \pm 1.1 \mathrm{nA}, n=$ $7, p>0.99, t=0.6, \mathrm{df}=35$; two-way ANOVA with post hoc comparison). Likewise, minimal amplitudes did not differ either for different ages or between genotypes (developmental effect: Fmr1 KO $p=0.24$, one-way ANOVA, WT 0.12, Kruskal-Wallis test; WT vs Fmr1 KO at P21, $1.3 \pm 0.7 \mathrm{nA}$ vs $0.55 \pm 0.12 \mathrm{nA}, p=$ 0.31 , unpaired $t$ test with Welch's correction). Similarly, shortterm depression in $4 \mathrm{WT}$ animals and $3 \mathrm{KO}$ animals remained unaltered $(50 \mathrm{~Hz}$ : WT $0.22 \pm 0.05$ vs $\mathrm{KO} 0.20 \pm 0.05 ; 100 \mathrm{~Hz}$ : $0.16 \pm 0.04$ vs $0.19 \pm 0.05 ; 200 \mathrm{~Hz}: 0.09 \pm 0.02, n=8$ vs $0.12 \pm$ $0.04, n=6, p>0.99, F=0.04$; $\mathrm{df}=37$; two-way ANOVA) (Fig. $5 E$ ). Additionally, spontaneous IPSC amplitude, frequency, and decay time remained largely unaffected (Fig. 5F). Only spontaneous IPSC frequency was transiently increased at P14 but unchanged earlier and later during development (P8: WT $1.4 \pm 0.3$, $n=11 \mathrm{~Hz}$ vs KO $1.9 \pm 0.3 \mathrm{~Hz}, n=4 ; p=0.7, t=1.2 ; \mathrm{P} 14$ : WT $2.2 \pm 0.2 \mathrm{~Hz}, n=15 \mathrm{vs} \mathrm{KO} 3.6 \pm 0.5 \mathrm{~Hz}, n=9, p=0.002, t=3.6$; P20: WT $1.9 \pm 0.1 \mathrm{~Hz}, n=14$ vs KO $2.0 \pm 0.25, \mathrm{~Hz} n=12, p>$ $0.99, t=0.3, \mathrm{df}=54$; two-way ANOVA with post hoc comparison) (Fig. $4 F$ ). Together, these findings argue against a longer lasting effect of FMRP on the development of glycinergic inputs to the LSO and reveal an altered input balance in favor of excitation in LSO neurons of Fmr1 KO mice.

\section{Passive and active membrane properties are only slightly affected in Fmr1 KO mice in vitro}

Changes in membrane excitability play a remarkable role in the heightened excitability observed in cortical and subcortical circuits of FXS mice (Contractor et al., 2015). To investigate whether ion channel composition and function of LSO neurons are also affected by the loss of FMRP, we measured peak and steady-state voltage responses to hyperpolarizing and depolarizing current injections in LSO neurons of WT and Fmr1 KO mice. Only at P21 did the current-voltage relationship reveal a larger voltage response in the hyperpolarizing range in Fmrl KO mice (WT $n=39$ vs $\mathrm{KO} n=25$, peak: $p=0.01, F=7.1, \mathrm{df}=32$; steady state: $p=0.002, F=10.7$, $\mathrm{df}=35$, two-way ANOVA; post hoc comparison peak: $p<0.05$ for $-600 \mathrm{pA}$ to $-400 \mathrm{pA}$; steady state: $p<0.05$ for $-600 \mathrm{pA}$ to $-200 \mathrm{pA}$ and $500 \mathrm{pA}$ ) (Fig. $6 A, B$ ). At the resting potential, input resistance did not differ between genotypes (Fig. 6C,D; Table 1). Only few voltage-gated ion channels operate in the hyperpolarizing range, of which the HCN channel family is the major contributor. We therefore explored whether HCN channels are downregulated in Fmr1 KO LSO neurons by measuring the pharmacologically isolated HCN currents (Ih). Both Ih amplitude and half-maximal activation did not differ between genotypes (Table 2), indicating that, unlike hippocampal neurons and cortical neurons, HCN channels are not affected in LSO neurons, and other channels must account for this small increase in input resistance. Other membrane properties, including resting membrane potential (RMP) and membrane time constant $(\tau)$, remained essentially unaffected (Fig. 6E,F; Table 1). Together, these findings indicate only subtle alterations in voltagegated ion channel composition in the Fmr1 KO LSO neurons.

FMRP has recently been shown to regulate action potential (AP) properties via BK channel modulation in hippocampal and
Table 1. Basic membrane properties of LSO neurons in WT and Fmr1 K0 mice ${ }^{a}$

\begin{tabular}{|c|c|c|c|c|}
\hline & $P^{P e a k} R_{\text {in }}(M \Omega)$ & $S S R_{\text {in }}(m \Omega)$ & RMP (mV) & $\tau(\mathrm{ms})$ \\
\hline \multicolumn{5}{|l|}{ P8 } \\
\hline WT $(n=17)$ & $189.4 \pm 21.5$ & $101.3 \pm 11.1$ & $-57.40 \pm 1.0$ & $17.28 \pm 1.87$ \\
\hline $\operatorname{Fmr1~K0}(n=16)$ & $217.1 \pm 24.1$ & $92.50 \pm 7.33$ & $-61.08 \pm 1.1$ & $21.16 \pm 2.12$ \\
\hline$p$ & 0.55 & $>0.99$ & 0.024 & 0.014 \\
\hline \multicolumn{5}{|l|}{ P14 } \\
\hline WT $(n=16)$ & $70.42 \pm 7.41$ & $37.41 \pm 5.2$ & $-49.82 \pm 0.8$ & $3.95 \pm 0.51$ \\
\hline $\operatorname{Fmr1} \mathrm{KO}(n=15)$ & $75.70 \pm 14.24$ & $43.20 \pm 7.4$ & $-50.54 \pm 1.4$ & $3.96 \pm 0.90$ \\
\hline$p$ & $>0.99$ & $>0.99$ & $>0.99$ & $>0.99$ \\
\hline \multicolumn{5}{|l|}{ P21 } \\
\hline WT $(n=39)$ & $42.75 \pm 1.5$ & $22.04 \pm 0.63$ & $-50.31 \pm 0.52$ & $2.0 \pm 0.14$ \\
\hline $\operatorname{Fmr1} \mathrm{KO}(n=20)$ & $54.03 \pm 5.0$ & $28.54 \pm 2.91$ & $-50.06 \pm 0.6$ & $1.95 \pm 0.22$ \\
\hline$p$ & $>0.99$ & $>0.99$ & $>0.99$ & $>0.99$ \\
\hline
\end{tabular}

${ }^{a}$ Input resistance $\left(R_{\text {in }}\right)$ was measured at the peak and the steady state (SS) response to a $-100 \mathrm{pA}$ current pulse. RMP, Resting membrane potential. $p$ values: two-way ANOVA followed by Bonferroni post-tests.

Table 2. Basic properties of the hyperpolarization-activated current (Ih) in WT and Fmr1 KO LSO neurons ${ }^{a}$

\begin{tabular}{lll}
\hline & Current $(\mathrm{nA})$ at $-95 \mathrm{mV}$ & Maximum half-activation $(\mathrm{mV})$ \\
\hline P21 & & \\
WT $(n=10)$ & $2.64 \pm 0.13$ & $-71.02 \pm 1.09$ \\
Fmr7 K0 $(n=12)$ & $2.47 \pm 0.22$ & $-70.54 \pm 1.47$ \\
$p$ & 0.53 & 0.79 \\
\hline
\end{tabular}

${ }^{a}$ Voltage-clamp recordings were obtained in the presence of the following (in $\mathrm{mm}$ ): 13,4-diaminopyridine, 10 TEA-Cl, $0.2 \mathrm{BaCl}_{2}, 0.001 \mathrm{TTX}, 0.05 \mathrm{NiCl}_{2}, 0.1 \mathrm{CdCl}_{2}, 0.01 \mathrm{DNQX}, 0.025 \mathrm{DL}-\mathrm{AP5}$, and 0.001 strychnine, to block other voltage-gated conductances.

cortical neurons in a translation-independent manner (Deng et al., 2013). Similarly, impaired plasticity of voltage-gated $\mathrm{K}^{+}$ channels in MNTB neurons leads to increased firing rates in FXS mice (Brown and Kaczmarek, 2011). Therefore, we wanted to know whether AP properties of LSO neurons are also affected by FMRP loss (Fig. 7A). We observed that the action potential halfwidth was broadened and the latency was shortened in the developing LSO of Fmr1 KO mice (Fig. 7 B, C; Table 3). In contrast, AP amplitude and voltage threshold remained unchanged (Fig. $7 D, E$; Table 3 ). Together, these data suggest a modest increase in excitability in LSO neurons of FXS mice.

\section{Increased firing rates and broadened tuning curves in the LSO of FXS mice}

The elevated excitatory input drive from the ipsilateral ear and the modest increase in excitability suggested that single neuron responses to sound stimulation are elevated in FXS mice. We therefore characterized single-unit responses of LSO neurons to monaural, ipsilateral sound stimulation in anesthetized WT $(N=3)$ and Fmr1 KO animals $(N=9)$ (Fig. $8 A)$. ILD sensitivity was used as a criterion to select for LSO principal neurons. Additionally, recording sites were verified by iontophoretic application of HRP and subsequent histological procedures (Fig. 8B). All recorded units (26 WT, $44 \mathrm{KO}$ ) were located within the borders of the LSO according to HRP labeling and subsequent reconstruction of stereotactic measures. Spontaneous firing rates, ranging from 0 to $65 \mathrm{~Hz}$, were not correlated with the neurons' characteristic frequency and did not differ between $\mathrm{KO}(n=16)$ and WT mice $(n=23)$ (Fig. $8 C$ ). Similarly, first spike latencies (WT: $8.03 \pm 0.56 \mathrm{~ms}, n=26$; KO: $8.87 \pm 0.64 \mathrm{~ms}, n=43$; Mann-Whitney: $p=0.1808)$ and thresholds WT: $21.5 \pm 3.1 \mathrm{~dB}$, $n=20$; KO: $26.6 \pm 2.6 \mathrm{~dB}, n=41$; Mann-Whitney: $p=0.2515$ ) did not differ between genotypes (Fig. $8 D, E$ ). Yet, the firing pattern in response to pure tone stimulation at the neurons characteristic frequency differed profoundly between WT and KO 
A

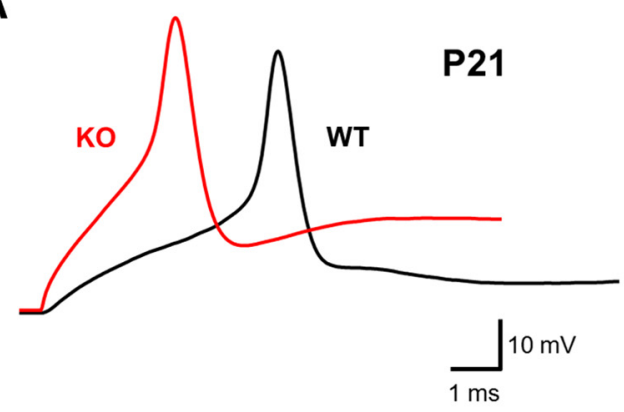

B

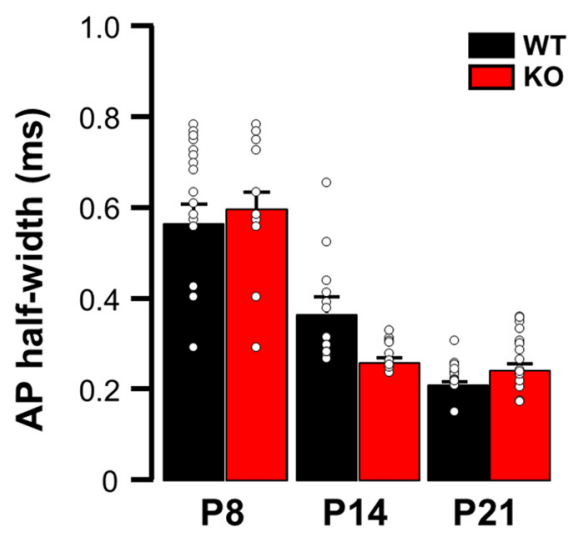

D

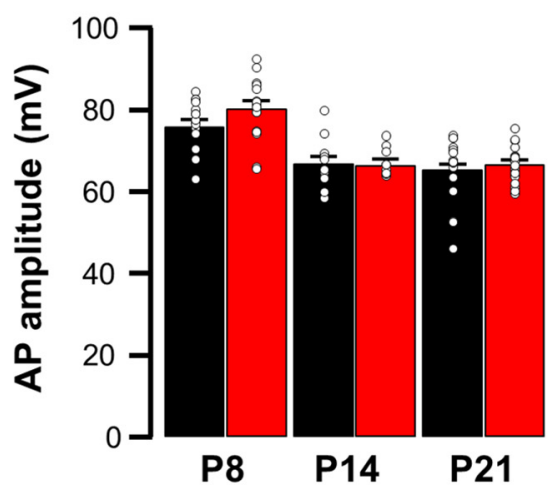

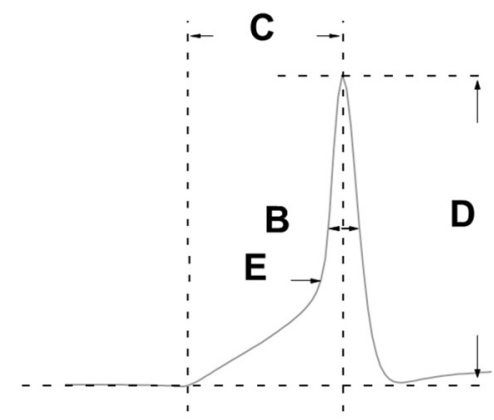

C

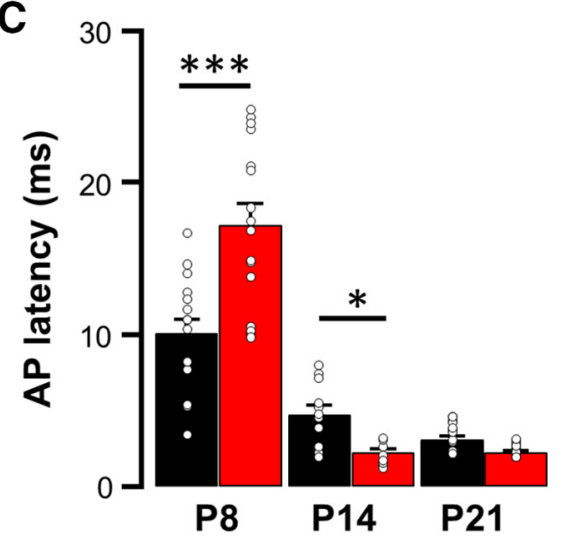

E

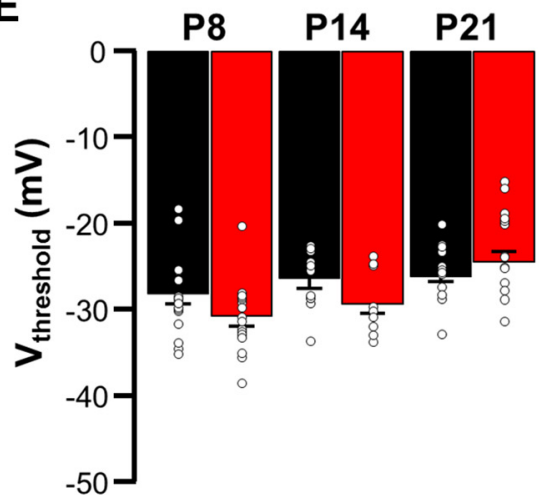

Figure 7. Loss of FMRP leads to an AP broadening and a decrease in AP latency in LSO neurons. $A$, Sample traces of APs in LSO neurons of WT and Fmr $1 \mathrm{KO}$ mice in response to suprathreshold current injections. Inset, AP shape features measured. $\boldsymbol{B}-\boldsymbol{E}$, Analysis of the active membrane properties reveals that AP half-width $(\boldsymbol{B})$ is increased and AP latency decreased $(\boldsymbol{C})$, whereas AP amplitude $(\boldsymbol{D})$ and voltage threshold $(\boldsymbol{E})$ remain unaltered in LSO neurons of Fmr1 mice. Bar graphs represent mean \pm SEM. ${ }^{*} p<0.05$ (two-way ANOVA followed by Bonferroni post tests). ${ }^{* * *} p<0.001$ (two-way ANOVA followed by Bonferroni post tests).

animals. Whereas LSO neurons of WT animals responded almost exclusively with an onset firing pattern, a large number of $\mathrm{KO}$ LSO neurons fired sustained throughout the entire stimulus presentation of $100 \mathrm{~ms}$ (Fig. 8F). This resulted in considerably more spikes per stimulus in KO compared with control animals (WT: $1.6 \pm 0.14$ spikes/stimulation, $n=26$; KO: $9.3 \pm 1.9$ spikes/ stimulation, $n=43$; Mann-Whitney: $p=0.0005$ ) (Fig. $8 G$ ). When sound intensity was gradually increased, most Fmr1 KO neurons $(n=43)$ with sustained firing pattern fired more action potentials, whereas WT neurons $(n=25)$ with an onset-type firing responded mostly once at the beginning of the stimulus regardless of sound intensity (Fig. $8 H$ ). The variability in response pattern in Fmrl KO neurons was not dependent on the sex of the animals (data not shown). We speculate that the increased firing rate might contribute to the observed hypersensitivity to sounds in Fmrl KO mice.

The increased number of excitatory inputs converging onto a single LSO neuron indicates that LSO neurons in FXS mice receive inputs from more cochlear nucleus neurons with presumably different frequency tuning. As a consequence, frequency tuning should be broader in Fmr1 KO compared with WT animals. Figure $8 I$ shows the frequency response area of two representative LSO neurons of WT and Fmrl KO animals. Generally, tuning curves of Fmr1 KO LSO neurons were considerably broader compared with WT neurons. Tuning bandwidth was quantified by measuring the Q10 and Q30 value $(\mathrm{CF} /$ tuning bandwidth at 10 and $30 \mathrm{~dB}$ above threshold). Pooled data revealed a significant decrease of Q10 and Q30 values in $\mathrm{KO}$ mice, 


\begin{tabular}{|c|c|c|c|c|}
\hline & AP width (ms) & Latency (ms) & $\begin{array}{l}\text { AP } \\
\text { amplitude (pA) }\end{array}$ & $\begin{array}{l}\text { Voltage } \\
\text { threshold }(\mathrm{mV})\end{array}$ \\
\hline \multicolumn{5}{|l|}{ P8 } \\
\hline WT $(n=17)$ & $0.57 \pm 0.04$ & $10.09 \pm 0.91$ & $76.06 \pm 1.6$ & $-28.27 \pm 1.1$ \\
\hline $\operatorname{Fmr1} \mathrm{KO}(n=16)$ & $0.60 \pm 0.04$ & $17.24 \pm 1.36$ & $80.26 \pm 1.9$ & $-30.91 \pm 1.0$ \\
\hline$p$ & $>0.99$ & $<0.001$ & 0.67 & 0.59 \\
\hline \multicolumn{5}{|l|}{ P14 } \\
\hline WT $(n=16)$ & $0.376 \pm 0.034$ & $4.73 \pm 0.56$ & $67.04 \pm 1.57$ & $-26.49 \pm 1.0$ \\
\hline $\operatorname{Fmr} 1 \mathrm{KO}(n=15)$ & $0.26 \pm 0.01$ & $2.25 \pm 0.18$ & $66.50 \pm 1.47$ & $-29.43 \pm 0.9$ \\
\hline$p$ & $>0.99$ & 0.04 & $>0.99$ & 0.69 \\
\hline \multicolumn{5}{|l|}{ P21 } \\
\hline WT $(n=39)$ & $0.21 \pm 0.005$ & $3.11 \pm 0.18$ & $65.49 \pm 1.1$ & $-26.24 \pm 0.6$ \\
\hline $\operatorname{Fmr1} \mathrm{KO}(n=20)$ & $0.24 \pm 0.01$ & $2.28 \pm 0.1$ & $66.74 \pm 0.91$ & $-24.59 \pm 1.3$ \\
\hline$p$ & $>0.99$ & 0.72 & $>0.99$ & $>0.99$ \\
\hline
\end{tabular}

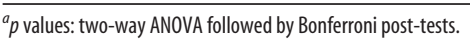

which were used as a measure for a broadening of bandwidth (Fig. 8J); Q10: $\mathrm{WT}=8.8 \pm 1.2, n=20 ; \mathrm{KO}=6.2 \pm 0.8, n=40$; Mann-Whitney: $p=0.0129 ; \mathrm{Q} 30$ : WT $=3.7 \pm 0.3, n=19 ; \mathrm{KO}=$ $2.9 \pm 0.3, n=37$; Mann-Whitney: $p=0.0186$ ). These data support the idea that frequency tuning of LSO neurons is compromised by the lack of FMRP, most likely as a result of the augmented excitatory input number.

\section{Shifted binaural sensitivity of LSO neurons in FXS mice}

LSO neurons encode ILDs by integrating ipsilateral excitatory and contralateral inhibitory inputs. The imbalance of these inputs in FXS mice, as observed in our in vitro studies, suggests that ILD sensitivity is affected by the loss of Fmr1. We measured ILD sensitivity by increasing contralateral acoustic stimulation while keeping the ipsilateral sound intensity constant. For both Fmr1 WT and KO mice, LSO neurons responded maximally when the contralateral stimulus intensity was minimal. Increasing contralateral sound intensity gradually reduced the number of spikes and the neurons eventually stopped firing (Fig. 9A). However, in agreement with the imbalance of excitation and inhibition in Fmrl $\mathrm{KO}$ mice, these neurons required louder contralateral sound intensities to reduce spiking activity. To quantify ILD sensitivity of Fmr1 WT and KO neurons, a Boltzmann function was fitted to the ILD response function, and the point of halfmaximal inhibition and the slope factor were calculated for those neurons where half-maximal inhibition fell within the biological relevant range of mice ( $\pm 20 \mathrm{~dB}$ ) (Fig. $9 A$, insets). The Boltzmann slope factor describes the steepness of the curve, such that larger values correspond to a less steep curve. On average, LSO neurons of $\mathrm{KO}$ mice required almost $10 \mathrm{~dB}$ louder sounds at the contralateral ear for half-maximal inhibition compared with WT mice (half-maximal inhibition: WT: ILD $=10.1 \pm 1.2 \mathrm{~dB}, n=25, \mathrm{KO}$ : $\mathrm{ILD}=2.7 \pm 2.0 \mathrm{~dB}, n=27, p=0.003, t=3.2, \mathrm{df}=41$; unpaired $t$ test with Welch's correction) (Fig. 9B). Moreover, the decline in firing by increasing contralateral sound intensity was less steep in Fmr1 animals, resulting in an increased slope factor in these animals (slope factor: WT: $5.2 \pm 0.8, n=22, \mathrm{KO}: 8.9 \pm 1.0, n=26$, $p=0.0096, t=2.7, \mathrm{df}=46$; unpaired $t$ test:) (Fig. 9C). Together, these data demonstrate that a lack of FMRP profoundly alters monaural and binaural auditory processing at the level of the auditory brainstem, which might underlie the observed auditory processing deficits and hypersensitivity observed in FXS patients.

\section{Discussion}

The present study revealed that the functional maturation of synapses in the LSO is severely altered in FXS mice. This disturbed development resulted in enhanced excitatory input strength from the ipsilateral side and an excessive number of excitatory synapses, whereas synaptic release properties and the strength of individual synapses remained unaffected. Inhibitory glycinergic inputs, activated from the contralateral side, were unchanged in Fmr1 KO mice. This altered balance between ipsilateral excitation and contralateral inhibition was paralleled by a modest increase in input resistance of LSO neurons. These changes in LSO circuitry are likely to be the underlying cause of our observed sound-processing deficits in adult FXS mice. LSO neurons in these mice exhibited enhanced firing rates, broadened tuning curves and shifted ILD functions in response to monaural and binaural sound stimulation.

\section{FMRP dependent developmental remodeling of excitatory inputs to LSO neurons}

One important finding of this study is that, already at the level of the brainstem, the loss of FMRP severely affects the developmental maturation of excitatory projections, resulting in impaired auditory processing in LSO neurons. Our data show that, during the first $10 \mathrm{~d}$ after hearing onset, the number of excitatory synapses impinging on individual LSO neurons is significantly enhanced, whereas presynaptic and postsynaptic properties of single synapses seem to be unaffected. This is in line with a previous study that shows a similar increase in the VGluT2immunolabeled area in the LSO of Fmr1 KO mice (Rotschafer et al., 2015). The same study also reports an increase in vesicular GABA transporter (VGAT) immunoreactivity in the LSO of FXS mice, whereas our data suggest that glycinergic inputs from the MNTB remain unaffected. This discrepancy could be explained by the fact that the relative ratio of VGAT and glycine transporter (GlyT2) activity at these synapses is not well understood and VGAT levels might not be a reliable marker for glycinergic synaptic efficacy. One can also speculate that developmental changes in the relative GABA/glycine content in the FXS mice could explain this divergence.

An increased excitatory connectivity has been reported in several other parts of the brain in FXS patients and mice. Indeed, augmented spine counts, reflecting excessive excitatory inputs, were one of the earliest observations in cortical areas of patients and in mouse models of FXS (Bagni and Greenough, 2005). This is supported by further evidence that FMRP loss causes deficits in synaptic pruning in sensory cortical areas leading to axonal overgrowth (Galvez and Greenough, 2005; Galvez et al., 2005). Furthermore, FMRP promotes cell-to-cell pruning of excitatory connections in hippocampal cell cultures and in the neocortex (Pfeiffer and Huber, 2007; Patel et al., 2014).

In the LSO, the observed enhanced excitatory input number could be explained by a lack of synaptic pruning or by de novo sprouting. Synaptogenesis in the LSO occurs at early embryonic stages (Kandler and Friauf, 1995), which is followed by functional synaptic pruning of both excitatory and inhibitory inputs during the first postnatal week (Kim and Kandler, 2003; Kandler and Gillespie, 2005; Case et al., 2011b; Hirao et al., 2015). Because at P8 excitatory input strength did not differ between control and FXS mice, FMRP loss does not seem to inhibit the initial functional pruning. Only several days later, paralleled by the peak expression levels of FMRP in WT animals, excitatory input strength was considerably enhanced. One explanation is that anatomical pruning, which follows functional pruning by several days (Clause et al., 2014), is mostly affected by FMRP loss, and previously silent synapses are reactivated in the absence of FMRP. However, it is also possible that de novo excitatory synapse for- 
A

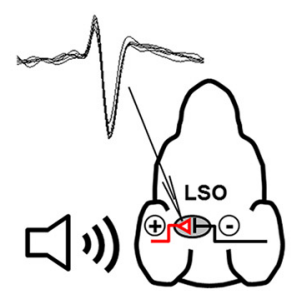

B

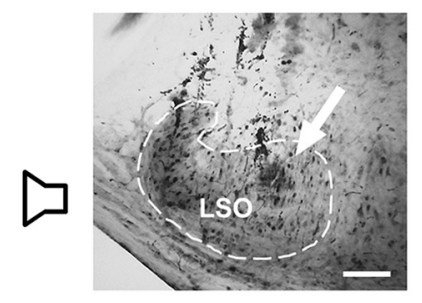

C

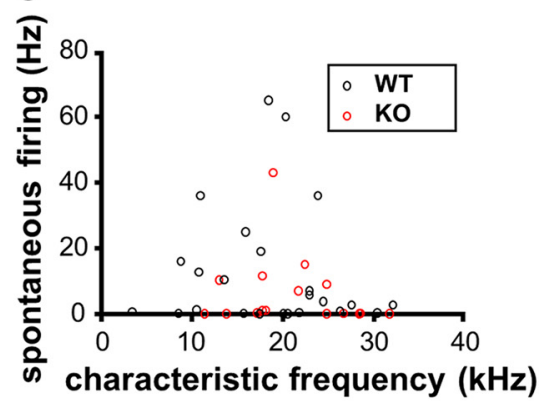

D

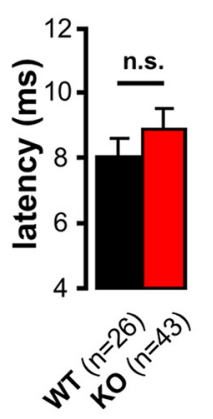

H
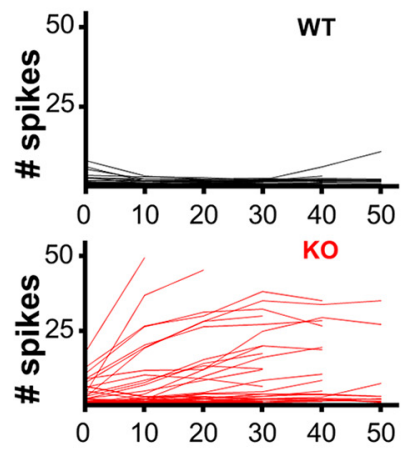

dB above threshold

E

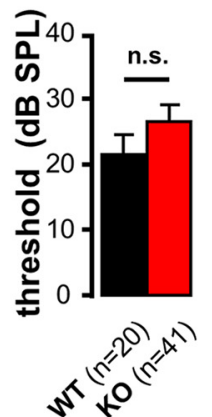

I
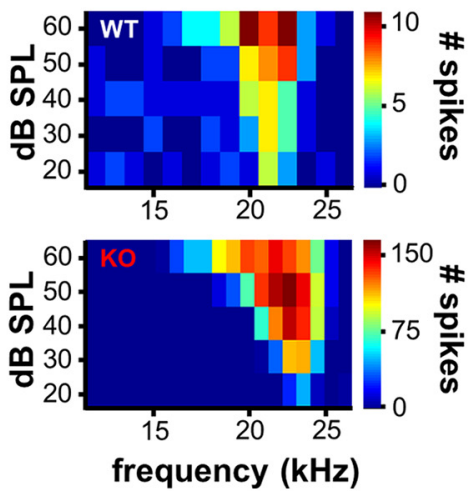

G

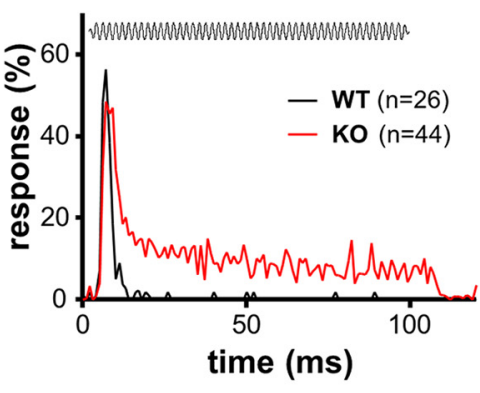

J

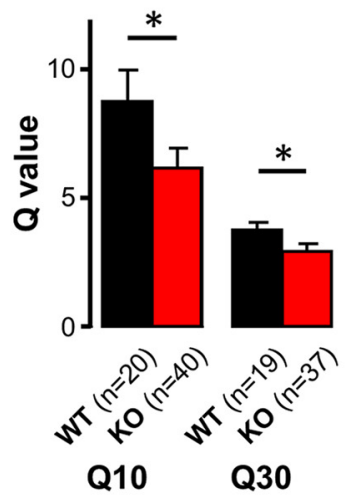

Figure 8. Increased firing rate and broadened frequency tuning in the $L S O$ of $F m r 1 \mathrm{KO}$ mice. $A$, Schematic of in vivo $L S O$ recording procedure. Exemplary spike shapes provide proof for single-unit recordings. B, HRP-labeled recording site in the LSO with Niss counterstain. Scale bar, $100 \mu \mathrm{m}$. C, Frequency tuning has no effect on spontaneous activity both in WT and in K0. Each circle represents one cell. $\boldsymbol{D}$, First spike latencies and $(\boldsymbol{E})$ hearing thresholds were similar in both genotypes. $\boldsymbol{F}$, Averaged spike response of WT and KO LSO neurons reveals more sustained activity throughout the stimulus presentation in $\mathrm{KO}$ mice. $\boldsymbol{G}$, Mean number of spikes per acoustic stimulation (100 ms). Each circle represents one cell. $\boldsymbol{H}$, Spike rate dependence on sound pressure level for each individual neuron in WT and KO mice, showing no change in the number of spikes for WT neurons with rising sound pressure level at $C F$, whereas spike numbers gradually increased for many $K 0$ neurons. Response threshold is set to $0 \mathrm{~dB}$ for each individual neuron. $I$, Frequency response areas of two representative LSO neurons, each patch showing the total number of spikes of four repetitions. $J, Q$ values as a measure for frequency tuning sharpness, expressing the bandwidth of the tuning curve 10 and $30 \mathrm{~dB}$ above threshold. Smaller $Q 10$ and Q30 values indicate significantly broader tuning in KO animals. Bar graphs represent mean \pm SEM. Mann-Whitney test was used to evaluate differences between genotypes. $p<0.05$ was considered statistically significant. ${ }^{*} p<0.05{ }^{* * * *} p<$ 0.001 .

mation occurs during this time in the LSO of FXS mice, leading to the enhanced excitatory connectivity. Currently, the molecular mechanisms involved in these processes are unknown. It is possible that mGluRs contribute to this effect as observed in other parts of the brain (Bear et al., 2004). In the hippocampus and the cerebellum of the FXS mouse model, mGluR-mediated LTD is enhanced (Huber et al., 2002; Koekkoek et al., 2005), and systemic application of mGluR5 antagonists ameliorates Fragile X symptoms in these animals (Yan et al., 2005; Pop et al., 2013). In the LSO, different forms of mGluRs are expressed at presynaptic and postsynaptic sites mainly early during development (Ene et al., 2003, 2007; Nishimaki et al., 2007). In this period, activation of Group I mGluRs on LSO principal neurons evokes pronounced calcium influx and prolonged depolarization (Kotak and Sanes, 1995; Ene et al., 2003). To what extent mGluR signaling contributes to the refinement of excitatory synapses and whether this mechanism is altered in the LSO of Fmrl KO mice remains to be shown.

Changes in intrinsic properties and excitability in vitro and in vivo in FXS mice

In addition to the profound reorganization of synaptic inputs, we also observed a small but consistent increase in input resistance in the hyperpolarizing and depolarizing range. Surprisingly, HCN 
A

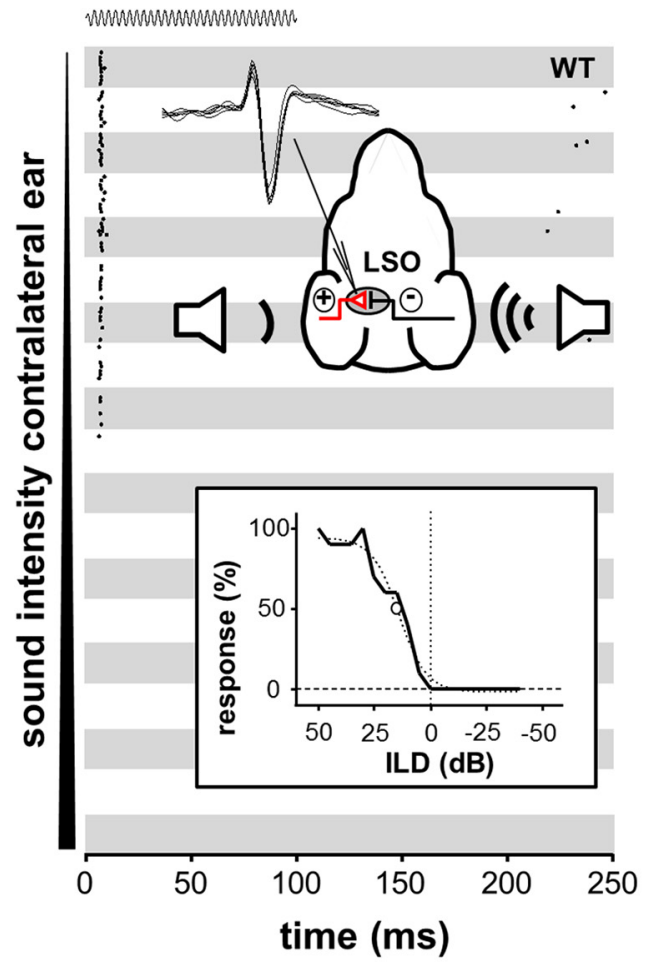

B

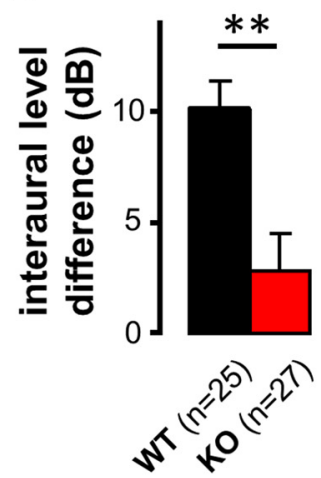

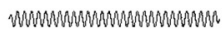

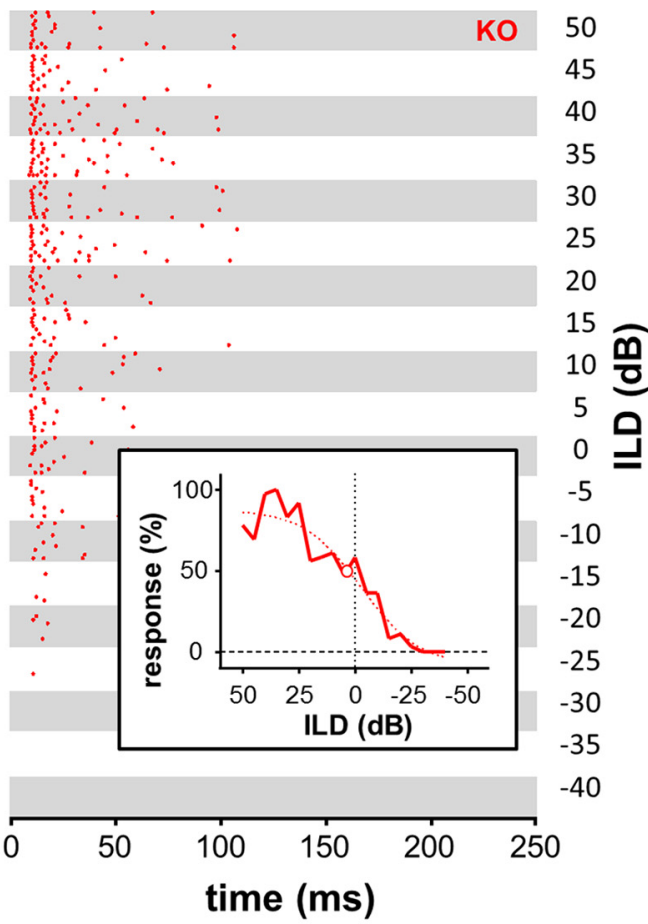

D

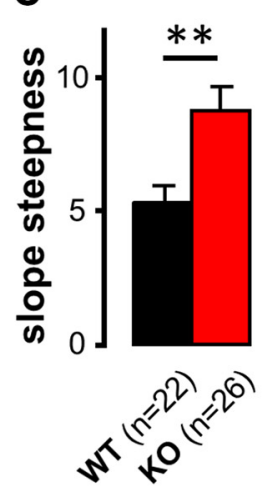

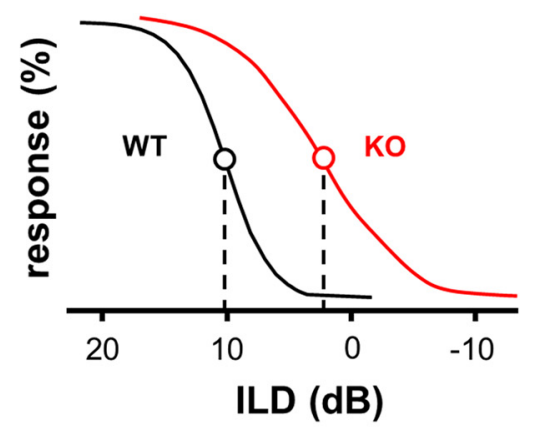

Figure 9. Processing of ILDs is affected by the loss of FMRP. A, Raster dot plots of two exemplary LSO recordings of a WT (left) and KO (right) mouse presenting various ILDs. Each row represents 10 repetitions per ILD combination at neuron's CF (ipsilateral $20 \mathrm{~dB}$ above threshold), each dot indicates one spike. Schematic depicts ILD recording procedure. Insets, Corresponding ILD functions, including sigmoidal fit and point of half-maximal inhibition. In the WT neuron ( $C F=22.9 \mathrm{kHz}$ ), ipsilateral intensity remained at $40 \mathrm{~dB} \mathrm{SPL}(20 \mathrm{~dB}$ above threshold). Contralateral intensity ranged from $-10 \mathrm{~dB}$ SPL to $80 \mathrm{~dB}$ SPL. Point of half-maximal inhibition was at ILD $=-14 \mathrm{~dB}$. In the $K 0$ neuron (CF $=8.6 \mathrm{kHz}$ ), ipsilateral intensity remained at $50 \mathrm{~dB}$ SPL ( $20 \mathrm{~dB}$ above threshold). Contralateral intensity ranged from 0 to $90 \mathrm{dBSPL}$. Point of half-maximal inhibition was at ILD $=-5 \mathrm{~dB}$. B, ILD of half-maximal inhibition is increased in K0 animals. C, An increasing slope steepness of the ILD function in KO mice represents a slower decline due to prevailing excitation. $\boldsymbol{D}$, Schematic of ILD functions in the LSO of WT and Fmr1 animals. Circles represent point of half-maximal inhibition (point of inflection). Bar graphs represent mean \pm SEM. Unpaired $t$ test with Welch's correction or Mann-Whitney test was used accordingly to evaluate differences between genotypes. $p<0.05$ was considered statistically significant. ${ }^{* *} p<0.001$.

currents, the main currents activated by hyperpolarization in LSO neurons (Leao et al., 2005; Hassfurth et al., 2009), were unchanged in FXS mice. Several other voltage-gated ion channels may be directly or indirectly modulated by the loss of FMRP (Contractor et al., 2015; Ferron, 2016). For example, FMRP directly modulates the gating of the sodium-activated $\mathrm{K}^{+}$channel Slack in MNTB neurons (Brown et al., 2010). These channels are also expressed in the LSO (Rizzi et al., 2016), and downregulation of these currents might contribute to the observed increase in input resistance. Likewise, the calcium-activated $\mathrm{K}^{+}$channel BK is directly affected by the loss of FMRP (Contractor, 2013; Deng et al., 2013). However, this channel seems to be only marginally expressed in LSO neurons (unpublished data) and is therefore unlikely to be a contributing factor.

One interesting observation in our study was that approximately half of the LSO neurons in FXS mice fired substantially more spikes in response to pure tone sound stimulation compared with WT neurons. This could be explained by the excessive excitatory input drive we have observed in our in vitro experiments, but ion channel dysregulation might also be a contributing factor. But why is this change in firing pattern not apparent in our in vitro preparation, where onset spiking was also prevalent in FXS neurons? One simple explanation might be the difference in the developmental stage of the characterized neurons. Ion 
channel dysregulation might gradually develop over several weeks after synaptic remodeling has occurred and would thus be more apparent in the adult animals used in our in vivo experiments. Another, more striking explanation for the lack of firing pattern changes in vitro could be an FMRP-induced activitydependent regulation of $\mathrm{K}^{+}$channels. Indeed, this was shown for neurons in the MNTB, where the lack of FMRP resulted in a loss of activity dependent upregulation of Slack- and Kv3-mediated currents (Brown et al., 2010; Strumbos et al., 2010; Brown and Kaczmarek, 2011). Both Slack and Kv3 channels are highly expressed in LSO neurons (Li et al., 2001; Rizzi et al., 2016). Therefore, persistent sound stimulation during our in vivo experiments might upregulate $\mathrm{K}^{+}$channel conductance in WT animals, thereby reducing spiking to ongoing sound presentation. This is also in line with the massive reduction in K-conductances during the first half hour after sectioning the brain as observed in the auditory brainstem (Steinert et al., 2011). This adaptation mechanism might be impaired in FXS LSO neurons and would thus lead to more sustained firing patterns in these animals.

\section{Functional implications of increased brainstem connectivity for sensory processing in FXS}

Sensory processing deficits in FXS patients are similar across different senses manifesting as hypersensitivity to moderate sensory stimulation and decreased sensory discrimination ability. Most previous studies on sensory processing in FXS have focused on cortical areas, including the auditory, visual, and somatosensory cortex. In most cases, FXS-related cortical changes include increased excitability of neural circuits, altered spike responses to sensory stimulation, and reduced detection thresholds of sensory patterns (Rotschafer and Razak, 2013; Knoth et al., 2014; Juczewski et al., 2016; Franco et al., 2017). These deficits usually arise during the critical period, when sensory cortical circuits are formed, as a consequence of defective synaptic plasticity (Harlow et al., 2010; Kim et al., 2013). To what extent these abnormal plasticity mechanisms are maintained throughout adulthood has not yet been clarified. Whereas all previous studies have pointed to impaired cortical sensory processing, our study implies that, already at the level of the brainstem, sensory processing is altered due to aberrant development of excitatory inputs during the critical period. Indeed, our observed auditory processing deficits in the LSO are rather similar compared with observations at the cortical level (Rotschafer and Razak, 2013). This indicated that at least part of these changes are transmitted from the brainstem to the cortex. It is thus likely that not only cortical areas are affected in FXS patients, but many brainstem areas show disturbed connectivity and function. This is in line with the wide expression of the FMRP protein in the mouse brain, suggesting an important role for this protein in the brainstem (Zorio et al., 2017).

Fragile X patients also suffer from communication problems, including delayed language acquisition, difficulties in speech recognition, also in noise, and speech production (Lozano et al., 2014; Rotschafer and Razak, 2014). These language deficits might be associated with basic language processing impairments, which initially occur in auditory brainstem circuits (Johnson et al., 2005; Reichenbach et al., 2016). Moreover, speech recognition in a noisy background is largely dependent on binaural sound processing. It is therefore likely that our observed deficits in monaural and binaural sound processing at the auditory brainstem level might be an underlying factor also for some of these communication abnormalities.

In conclusion, sensory and especially auditory hypersensitivity is a core symptom of FXS that can be easily tested in humans and experimental animals. In combination with its simple and well-characterized circuitry, the LSO and the auditory system could serve as an attractive model system to evaluate treatment options and efficacy, and correlate them to the cellular mechanisms underlying FXS syndrome.

\section{References}

Arinami T, Sato M, Nakajima S, Kondo I (1988) Auditory brain-stem responses in the fragile X syndrome. Am J Hum Genet 43:46-51. Medline

Bagni C, Greenough WT (2005) From mRNP trafficking to spine dysmorphogenesis: the roots of fragile X syndrome. Nat Rev Neurosci 6:376-387. CrossRef Medline

Baumann VJ, Lehnert S, Leibold C, Koch U (2013) Tonotopic organization of the hyperpolarization-activated current (Ih) in the mammalian medial superior olive. Front Neural Circuits 7:117. CrossRef Medline

Bear MF, Huber KM, Warren ST (2004) The mGluR theory of fragile X mental retardation. Trends Neurosci 27:370-377. CrossRef Medline

Ben-Sasson A, Hen L, Fluss R, Cermak SA, Engel-Yeger B, Gal E (2008) A meta-analysis of sensory modulation symptoms in individuals with autism spectrum disorders. J Autism Dev Disord 39:1-11. CrossRef Medline

Benson CG, Gross JS, Suneja SK, Potashner SJ (1997) Synaptophysin immunoreactivity in the cochlear nucleus after unilateral cochlear or ossicular removal. Synapse 25:243-257. CrossRef Medline

Braat S, Kooy RF (2015) The GABAA receptor as a therapeutic target for neurodevelopmental disorders. Neuron 86:1119-1130. CrossRef Medline

Brown MR, Kaczmarek LK (2011) Potassium channel modulation and auditory processing. Hear Res 279:32-42. CrossRef Medline

Brown MR, Kronengold J, Gazula VR, Chen Y, Strumbos JG, Sigworth FJ, Navaratnam D, Kaczmarek LK (2010) Fragile X mental retardation protein controls gating of the sodium-activated potassium channel Slack. Nat Neurosci 13:819-821. CrossRef Medline

Caicedo A, Eybalin M (1999) Glutamate receptor phenotypes in the auditory brainstem and mid-brain of the developing rat. Eur J Neurosci 11: 51-74. CrossRef Medline

Case DT, Zhao X, Gillespie DC (2011a) Functional refinement in the projection from ventral cochlear nucleus to lateral superior olive precedes hearing onset in rat. PLoS One 6:e20756. CrossRef Medline

Case DT, Zhao X, Gillespie DC (2011b) Functional refinement in the projection from ventral cochlear nucleus to lateral superior olive precedes hearing onset in rat. PLoS One 6:e20756. CrossRef

Castrén M, Pääkkönen A, Tarkka IM, Ryynänen M, Partanen J (2003) Augmentation of auditory $\mathrm{N} 1$ in children with fragile X syndrome. Brain Topogr 15:165-171. CrossRef Medline

Chen L, Toth M (2001) Fragile X mice develop sensory hyperreactivity to auditory stimuli. Neuroscience 103:1043-1050. CrossRef Medline

Clause A, Kim G, Sonntag M, Weisz CJ, Vetter DE, Rúbsamen R, Kandler K (2014) The precise temporal pattern of prehearing spontaneous activity is necessary for tonotopic map refinement. Neuron 82:822-835. CrossRef Medline

Contractor A (2013) Broadening roles for FMRP: big news for big potassium (BK) channels. Neuron 77:601-603. CrossRef Medline

Contractor A, Klyachko VA, Portera-Cailliau C (2015) Altered neuronal and circuit excitability in Fragile X syndrome. Neuron 87:699-715. CrossRef Medline

Curia G, Papouin T, Séguéla P, Avoli M (2009) Downregulation of tonic GABAergic inhibition in a mouse model of Fragile X syndrome. Cereb Cortex 19:1515-1520. CrossRef Medline

Deng PY, Rotman Z, Blundon JA, Cho Y, Cui J, Cavalli V, Zakharenko SS, Klyachko VA (2013) FMRP regulates neurotransmitter release and synaptic information transmission by modulating action potential duration via BK channels. Neuron 77:696-711. CrossRef Medline

Ene FA, Kullmann PH, Gillespie DC, Kandler K (2003) Glutamatergic calcium responses in the developing lateral superior olive: receptor types and their specific activation by synaptic activity patterns. J Neurophysiol 90 : 2581-2591. CrossRef Medline

Ene FA, Kalmbach A, Kandler K (2007) Metabotropic glutamate receptors in the lateral superior olive activate TRP-like channels: age- and experiencedependent regulation. J Neurophysiol 97:3365-3375. CrossRef Medline

Ferri R (1989) Brain-stem auditory evoked potentials in the fragile X syndrome. Am J Hum Genet 45:977-979. Medline

Ferron L (2016) Fragile X mental retardation protein controls ion channel expression and activity. J Physiol 594:5861-5867. CrossRef Medline 
Finlayson PG, Caspary DM (1989) Synaptic potentials of chinchilla lateral superior olivary neurons. Hear Res 38:221-228. CrossRef Medline

Franco LM, Okray Z, Linneweber GA, Hassan BA, Yaksi E (2017) Reduced lateral inhibition impairs olfactory computations and behaviors in a Drosophila model of Fragile X syndrome. Curr Biol 27:1111-1123. CrossRef Medline

Fuentes-Santamaría V, Alvarado JC, Rodríguez-de la Rosa L, Murillo-Cuesta S, Contreras J, Juiz JM, Varela-Nieto I (2016) IGF-1 deficiency causes atrophic changes associated with upregulation of VGluT1 and downregulation of MEF2 transcription factors in the mouse cochlear nuclei. Brain Struct Funct 221:709-734. CrossRef Medline

Galvez R, Greenough WT (2005) Sequence of abnormal dendritic spine development in primary somatosensory cortex of a mouse model of the fragile X mental retardation syndrome. Am J Med Genet A 135A:155-160. CrossRef Medline

Galvez R, Smith RL, Greenough WT (2005) Olfactory bulb mitral cell dendritic pruning abnormalities in a mouse model of the Fragile-X mental retardation syndrome: further support for FMRP's involvement in dendritic development. Brain Res Dev Brain Res 157:214-216. CrossRef Medline

Gillespie DC, Kim G, Kandler K (2005) Inhibitory synapses in the developing auditory system are glutamatergic. Nat Neurosci 8:332-338. CrossRef Medline

Grothe B, Pecka M, McAlpine D (2010) Mechanisms of sound localization in mammals. Physiol Rev 90:983-1012. CrossRef Medline

Harlow EG, Till SM, Russell TA, Wijetunge LS, Kind P, Contractor A (2010) Critical period plasticity is disrupted in the barrel cortex of Fmr1 knockout mice. Neuron 65:385-398. CrossRef Medline

Hassfurth B, Magnusson AK, Grothe B, Koch U (2009) Sensory deprivation regulates the development of the hyperpolarization-activated current in auditory brainstem neurons. Eur J Neurosci 30:1227-1238. CrossRef Medline

Hirao K, Eto K, Nakahata Y, Ishibashi H, Nagai T, Nabekura J (2015) Noradrenergic refinement of glutamatergic neuronal circuits in the lateral superior olivary nucleus before hearing onset. J Neurophysiol 114:19741986. CrossRef Medline

Hirtz JJ, Braun N, Griesemer D, Hannes C, Janz K, Löhrke S, Müller B, Friauf E (2012) Synaptic refinement of an inhibitory topographic map in the auditory brainstem requires functional CaV1.3 calcium channels. J Neurosci 32:14602-14616. CrossRef Medline

Huber KM, Gallagher SM, Warren ST, Bear MF (2002) Altered synaptic plasticity in a mouse model of fragile X mental retardation. Proc Natl Acad Sci U S A 99:7746-7750. CrossRef Medline

Johnson KL, Nicol TG, Kraus N (2005) Brain stem response to speech: a biological marker of auditory processing. Ear Hear 26:424-434. CrossRef Medline

Juczewski K, von Richthofen H, Bagni C, Celikel T, Fisone G, Krieger P (2016) Somatosensory map expansion and altered processing of tactile inputs in a mouse model of fragile X syndrome. Neurobiol Dis 96:201215. CrossRef Medline

Indig FE, Diaz-Gonzalez F, Ginsberg MH (1997) Analysis of the tetraspanin CD9-integrin alphaIIbbeta3 (GPIIb-IIIa) complex in platelet membranes and transfected cells. Biochem J 327:291-298. Medline

Kandler K, Friauf E (1995) Development of glycinergic and glutamatergic synaptic transmission in the auditory brainstem of perinatal rats. J Neurosci 15:6890-6904. Medline

Kandler K, Gillespie DC (2005) Developmental refinement of inhibitory sound-localization circuits. Trends Neurosci 28:290-296. CrossRef Medline

Kandler K, Clause A, Noh J (2009) Tonotopic reorganization of developing auditory brainstem circuits. Nat Neurosci 12:711-717. CrossRef Medline

Kim G, Kandler K (2003) Elimination and strengthening of glycinergic/ GABAergic connections during tonotopic map formation. Nat Neurosci 6:282-290. CrossRef Medline

Kim H, Gibboni R, Kirkhart C, Bao S (2013) Impaired critical period plasticity in primary auditory cortex of Fragile X model mice. J Neurosci 33:15686-15692. CrossRef Medline

Knoth IS, Lippé S (2012) Event-related potential alterations in fragile X syndrome. Front Hum Neurosci 6:264. CrossRef Medline

Knoth IS, Vannasing P, Major P, Michaud JL, Lippé S (2014) Alterations of visual and auditory evoked potentials in fragile X syndrome. Int J Dev Neurosci 36:90-97. CrossRef Medline

Koekkoek SK, Yamaguchi K, Milojkovic BA, Dortland BR, Ruigrok TJ, Maex
R, De Graaf W, Smit AE, VanderWerf F, Bakker CE, Willemsen R, Ikeda T, Kakizawa S, Onodera K, Nelson DL, Mientjes E, Joosten M, De Schutter E, Oostra BA, Ito M, et al. (2005) Deletion of FMR1 in Purkinje cells enhances parallel fiber LTD, enlarges spines, and attenuates cerebellar eyelid conditioning in Fragile X syndrome. Neuron 47:339-352. CrossRef Medline

Kotak VC, Sanes DH (1995) Synaptically evoked prolonged depolarizations in the developing auditory system. J Neurophysiol 74:1611-1620. Medline

Kotak VC, Korada S, Schwartz IR, Sanes DH (1998) A developmental shift from GABAergic to glycinergic transmission in the central auditory system. J Neurosci 18:4646-4655. Medline

Kulesza RJ, Mangunay K (2008) Morphological features of the medial superior olive in autism. Brain Res 1200:132-137. CrossRef Medline

Kulesza RJ, Lukose R, Stevens LV (2011) Malformation of the human superior olive in autistic spectrum disorders. Brain Res 1367:360-371. CrossRef Medline

Leao RN, Svahn K, Berntson A, Walmsley B (2005) Hyperpolarizationactivated (Ih) currents in auditory brainstem neurons of normal and congenitally deaf mice. Eur J Neurosci 22:147-157. CrossRef Medline

Li W, Kaczmarek LK, Perney TM (2001) Localization of two high-threshold potassium channel subunits in the rat central auditory system. J Comp Neurol 437:196-218. CrossRef Medline

Lozano R, Rosero CA, Hagerman RJ (2014) Fragile X spectrum disorders. Intractable Rare Dis Res 3:134-146. CrossRef Medline

Marco EJ, Hinkley LB, Hill SS, Nagarajan SS (2011) Sensory processing in autism: a review of neurophysiologic findings. Pediatr Res 69:48R-54R. CrossRef Medline

Musumeci SA, Bosco P, Calabrese G, Bakker C, De Sarro GB, Elia M, Ferri R, Oostra BA (2000) Audiogenic seizures susceptibility in transgenic mice with Fragile X syndrome. Epilepsia 41:19-23. CrossRef Medline

Nabekura J, Katsurabayashi S, Kakazu Y, Shibata S, Matsubara A, Jinno S, Mizoguchi Y, Sasaki A, Ishibashi H (2004) Developmental switch from GABA to glycine release in single central synaptic terminals. Nat Neurosci 7:17-23. CrossRef Medline

Nishimaki T, Jang IS, Ishibashi H, Yamaguchi J, Nabekura J (2007) Reduction of metabotropic glutamate receptor-mediated heterosynaptic inhibition of developing MNTB-LSO inhibitory synapses. Eur J Neurosci 26:323-330. CrossRef Medline

Noh J, Seal RP, Garver JA, Edwards RH, Kandler K (2010) Glutamate corelease at GABA/glycinergic synapses is crucial for the refinement of an inhibitory map. Nat Neurosci 13:232-238. CrossRef Medline

Olmos-Serrano JL, Paluszkiewicz SM, Martin BS, Kaufmann WE, Corbin JG, Huntsman MM (2010) Defective GABAergic neurotransmission and pharmacological rescue of neuronal hyperexcitability in the amygdala in a mouse model of Fragile X syndrome. J Neurosci 30:9929-9938. CrossRef Medline

Patel AB, Loerwald KW, Huber KM, Gibson JR (2014) Postsynaptic FMRP Promotes the pruning of cell-to-cell connections among pyramidal neurons in the L5A neocortical network. J Neurosci 34:3413-3418. CrossRef Medline

Pfeiffer BE, Huber KM (2007) Fragile X mental retardation protein induces synapse loss through acute postsynaptic translational regulation. J Neurosci 27:3120-3130. CrossRef Medline

Pop AS, Gomez-Mancilla B, Neri G, Willemsen R, Gasparini F (2013) Fragile X syndrome: a preclinical review on metabotropic glutamate receptor 5 (mGluR5) antagonists and drug development. Psychopharmacology (Berl) 231:1217-1226. CrossRef Medline

Reichenbach CS, Braiman C, Schiff ND, Hudspeth AJ, Reichenbach T (2016) The auditory-brainstem response to continuous, non-repetitive speech is modulated by the speech envelope and reflects speech processing. Front Comput Neurosci 10:47. CrossRef Medline

Rizzi S, Knaus HG, Schwarzer C (2016) Differential distribution of the sodium-activated potassium channels slick and slack in mouse brain. J Comp Neurol 524:2093-2116. CrossRef Medline

Rotschafer S, Razak K (2013) Altered auditory processing in a mouse model of Fragile X syndrome. Brain Res 1506:12-24. CrossRef Medline

Rotschafer SE, Razak KA (2014) Auditory processing in Fragile X syndrome. Front Cell Neurosci 8:19. CrossRef Medline

Rotschafer SE, Marshak S, Cramer KS (2015) Deletion of Fmrl alters function and synaptic inputs in the auditory brainstem. PLoS One 10: e0117266. CrossRef Medline 
Sanes DH (1993) The development of synaptic function and integration in the central auditory system. J Neurosci 13:2627-2637. Medline

Sanes DH, Friauf E (2000) Development and influence of inhibition in the lateral superior olivary nucleus. Hear Res 147:46-58. CrossRef Medline

Schwartz IR, Eager PR (1999) Glutamate receptor subunits in neuronal populations of the gerbil lateral superior olive1. Hear Res 137:77-90. CrossRef Medline

Selby L, Zhang C, Sun QQ (2007) Major defects in neocortical GABAergic inhibitory circuits in mice lacking the fragile $\mathrm{X}$ mental retardation protein. Neurosci Lett 412:227-232. CrossRef Medline

Sinclair D, Oranje B, Razak KA, Siegel SJ, Schmid S (2017) Sensory processing in autism spectrum disorders and Fragile $\mathrm{X}$ syndrome: from the clinic to animal models. Neurosci Biobehav Rev 76:235-253. CrossRef Medline

Steinert JR, Robinson SW, Tong H, Haustein MD, Kopp-Scheinpflug C, Forsythe ID (2011) Nitric oxide is an activity-dependent regulator of target neuron intrinsic excitability. Neuron 71:291-305. CrossRef Medline

Strumbos JG, Brown MR, Kronengold J, Polley DB, Kaczmarek LK (2010) Fragile X mental retardation protein is required for rapid experiencedependent regulation of the potassium channel Kv3.1b. J Neurosci 30: 10263-10271. CrossRef Medline

Tollin DJ (2003) The lateral superior olive: a functional role in sound source localization. Neuroscientist 9:127-143. CrossRef Medline

Van der Molen MJ, Van der Molen MW, Ridderinkhof KR, Hamel BC, Curfs LM, Ramakers GJ (2012) Auditory change detection in fragile X syn- drome males: a brain potential study. Clin Neurophysiol 123:1309-1318. CrossRef Medline

Wang Y, Sakano H, Beebe K, Brown MR, de Laat R, Bothwell M, Kulesza RJ Jr, Rubel EW (2014) Intense and specialized dendritic localization of the fragile X mental retardation protein in binaural brainstem neurons: a comparative study in the alligator, chicken, gerbil, and human. J Comp Neurol 522:2107-2128. CrossRef Medline

Weisz CJ, Rubio ME, Givens RS, Kandler K (2016) Excitation by axon terminal GABA spillover in a sound localization circuit. J Neurosci 36:911925. CrossRef Medline

Wisniewski KE, Segan SM, Miezejeski CM, Sersen EA, Rudelli RD (1991) The $\operatorname{Fra}(\mathrm{X})$ syndrome: neurological, electrophysiological, and neuropathological abnormalities. Am J Med Genet 38:476-480. CrossRef Medline

Yan QJ, Rammal M, Tranfaglia M, Bauchwitz RP (2005) Suppression of two major Fragile X Syndrome mouse model phenotypes by the mGluR5 antagonist MPEP. Neuropharmacology 49:1053-1066. CrossRef Medline

Zhang Y, Bonnan A, Bony G, Ferezou I, Pietropaolo S, Ginger M, Sans N, Rossier J, Oostra B, LeMasson G, Frick A (2014) Dendritic channelopathies contribute to neocortical and sensory hyperexcitability in Fmr1-/y mice. Nat Neurosci 17:1701-1709. CrossRef Medline

Zorio DA, Jackson CM, Liu Y, Rubel EW, Wang Y (2017) Cellular distribution of the fragile $\mathrm{X}$ mental retardation protein in the mouse brain. J Comp Neurol 525:818-849. CrossRef Medline 